\title{
ARTE RUPESTRE PREHISPÁNICO EN UN SITIO MINERO, RITUAL Y CARAVANERO DE LA PUNA DE SALTA: EL CASO DE CUEVA INCA VIEJO EN EL CONTEXTO MACRORREGIONAL DE LOS ANDES CENTRO-SUR \\ PREHISPANIC ROCK ART IN A MINING, RITUAL AND CARAVAN SITE OF THE PUNA DE SALTA: THE CASE OF CUEVA INCA VIEJO IN THE MACRO- REGIONAL CONTEXT OF THE SOUTH-CENTRAL ANDES
}

\author{
Gabriel E. J. López ${ }^{1}$, Silvina T. Seguí2, Patricia Solá ${ }^{3}$ \\ ${ }^{1}$ CONICET, Instituto de Arqueología, UBA. Buenos Aires, Argentina. Email:gabelope@yahoo.com \\ ${ }^{2}$ CONICET, Instituto de Arqueología, UBA. Buenos Aires, Argentina. \\ Email: silvisegui@gmail.com \\ ${ }^{3}$ CONICET, Instituto de Arqueología, UBA. Buenos Aires, Argentina. \\ Email: patriciasola@gmail.com
}

Presentado: 18/02/2021

Aceptado: 23/06/2021

\section{Resumen}

Se analiza y discute el arte rupestre prehispánico de Cueva Inca Viejo, Puna de Salta, en el marco de las actividades mineras, rituales y caravaneras desarrolladas en este sitio desde tiempos preincaicos hasta la expansión inca. El arte rupestre constituye un registro material apropiado para comprender aspectos económicos e ideológico/simbólicos como los que se expresan en la evidencia de la cueva. A su vez, se examinan procesos de transmisión cultural compartidos en escala amplia vinculados con el tráfico caravanero, tal como lo refleja la recurrencia de motivos de camélidos alineados y atados. Desde el punto de vista metodológico, se realiza una caracterización descriptiva y cuantitativa de las representaciones registradas, y se dan a conocer los primeros resultados EDX de dos pigmentos rojizos de capa y de una pintura negra relevada en uno de los paneles del sitio. Asimismo, se discuten los patrones de diseño y las temáticas distinguidas en Cueva Inca Viejo a partir de una comparación macrorregional con iconografías similares en distintos contextos de los Andes centro-sur. Finalmente, se evalúan las evidencias que permiten establecer una cronología relativa de las pinturas rupestres de la cueva. Estos análisis muestran cierta continuidad en la representación de figuras zoomorfas y antropomorfas en contextos prehispánicos. Sin embargo, se destaca que el arte rupestre de Cueva Inca Viejo presenta una intensa impronta incaica, de forma similar a lo observado a partir de otros indicadores arqueológicos. Esta particularidad se habría relacionado con la apropiación efectiva y simbólica de este sector de la Puna de Salta por parte del Imperio inca para la explotación minera del área.

Palabras clave: Arte rupestre, Andes centro-sur, minería, ritualidad, caravaneo 


\begin{abstract}
The pre-Hispanic rock art of Cueva Inca Viejo, Puna de Salta, is analyzed and discussed within the framework of mining, ritual and caravanning activities developed in this site from pre-Inca times to the Inca expansion. The rock art constitutes an appropriate material record to understand economic and ideological / symbolic aspects such as those expressed in the cave evidence. In turn, broad-scale shared cultural transmission processes linked to caravan traffic are examined, as reflected by the recurrence of aligned and tied camelid motifs. From the methodological point of view, a descriptive and quantitative characterization of the registered representations is carried out, and the first EDX results of two red pigments and one black paint of the site are reported. Likewise, the design patterns and themes distinguished in Cueva Inca Viejo are discussed from a macro-regional comparison with respect to similar iconographies in different contexts of the South-Central Andes. Finally, the evidence that allows establishing a relative chronology of the cave paintings is evaluated. Such analyzes show certain continuity in the representation of zoomorphic and anthropomorphic figures in pre-Hispanic contexts. However, it is highlighted that the rock art of Cueva Inca Viejo presents an intense Inca impact, in the same way as has been observed from other archaeological indicators. This particularity would have been related to the effective and symbolic appropriation of this sector of the Puna de Salta by the Inca Empire for the mining of the area.
\end{abstract}

Keywords: Rock art, South-Central Andes, mining, rituality, caravanning

\title{
Introducción
}

Esta investigación se focaliza en el estudio del arte rupestre prehispánico del sitio Cueva Inca Viejo, ubicado en la cuenca de Ratones, Puna de Salta, Noroeste argentino (Figura 1; López et al. 2015, 2018). El objetivo es analizar y discutir las pinturas rupestres reconocidas en el sitio en el contexto de las actividades mineras, rituales y caravaneras desarrolladas allí. Cueva Inca Viejo constituye un sitio importante para estudiar estas actividades, como así también para dar cuenta de la interrelación entre aspectos económicos y simbólicos. Las investigaciones emprendidas en el sitio han permitido reconocer diversos materiales arqueológicos vinculados con la minería, la ritualidad y el caravaneo en épocas preincaica e inca (López et al. 2018, 2020). En particular, se destaca que la cueva y el cerro Inca Viejo constituyen una fuente de turquesa que fue explotada en tiempos prehispánicos, principalmente durante la expansión del Tawantinsuyu (López et al. 2018).

El vínculo entre arte rupestre y contextos mineros ha sido reconocido en distintos sitios andinos (e.g. Cabello 2017; Garrido 2015; Sepúlveda et al. 2019; San Francisco y Ballester 2010, entre otros). Sin embargo, las figuras rupestres en espacios mineros no suelen hacer una alusión directa a esta actividad (e.g. San Francisco y Ballester 2010). De todas maneras, desde el punto de vista simbólico se ha postulado una estrecha relación de la actividad minera con personajes como el otorongo, una divinidad asociada con el jaguar (Bouysse-Cassagne 2005). Más claramente, las imágenes felínicas formaron parte de una realidad mítica recreada en prácticas rituales a lo largo de los Andes. En el caso minero, el 
otorongo se encontraba inmerso dentro de cultos chamánicos en los cuales se consumían sustancias alucinógenas como el cebil (Bouysse-Cassagne 2005; Pérez Gollán 1986). El consumo de estas sustancias y bebidas alcohólicas se ha considerado un aspecto fundamental de los rituales mineros. Las crónicas etnohistóricas indican la importancia de estas prácticas como medios para obtener la fuerza del otorongo en el emprendimiento minero. A su vez, los estudios etnográficos muestran cierta continuidad entre el culto prehispánico al otorongo y el culto al personaje mítico conocido como el tío (tiw) en las minas de Bolivia (Bouysse-Cassagne 2005). El entrelazamiento entre las prácticas económicas y rituales se explica mejor en el marco de la tradición andina que considera a los cerros y a las minas como huacas (espacios sagrados) a los que se les rendía culto (Coloca y López 2021; Salazar et al. 2013).

Estos antecedentes sirven para dar cuenta de que el arte rupestre de Cueva Inca Viejo no puede ser analizado como un registro aislado de las actividades minero-rituales que se llevaron a cabo en el sitio. El entrecruzamiento entre aspectos simbólicos y económicos es común en el mundo andino, tal como lo indican los "rituales de producción" (Martel 2010; Van Kessel 1989). En un sentido amplio, la ritualidad pudo haber sido central para la reproducción social (Coloca y López 2021). A través de las prácticas rituales se suele transmitir información fundamental para la vida social y la comunicación de normas, instituciones y liderazgos (Kerzter 1988). Los rituales forman parte de elaborados sistemas de creencia que estimulan el sentido de pertenencia, la cohesión y el compromiso de los grupos (Richerson y Henrich 2009). En contextos mineros, estos procesos de integración y cohesión social pudieron expresarse a partir de la replicación de motivos rupestres que reflejaban una ideología común o unificadora, como es el caso de antropomorfos con los brazos alzados (San Francisco y Ballester 2010).

En este marco, no puede soslayarse la naturaleza multidimensional del arte rupestre producto de diversos procesos tecnológicos y cognitivos (Fiore 2018). Más aún, debe considerarse su valor en la transmisión y comunicación de aspectos relevantes del comportamiento humano, incluyendo los ideológico/simbólicos y económicos, entre otros (Fiore 2018). A los fines de este trabajo, se hace hincapié en la importancia del arte rupestre para la transmisión de información cultural, tanto a nivel transgeneracional como horizontal (Muscio 2006, 2010). Al respecto, se ha señalado la existencia de flujos diferenciales de información visual pictórica en el Norte de Chile, los cuales implicaron la transmisión de conocimientos a partir de redes de interacción social en distintas escalas (Gallardo et al. 2012). En el caso de Cueva Inca Viejo, existe una recurrencia de caravanas pintadas; en consecuencia, el arte rupestre pudo haber tenido un rol importante en la comunicación de la interacción caravanera. Estos procesos habrían facilitado el traspaso de información, bienes y recursos a nivel macrorregional. Incluso, pudieron haber posibilitado el tráfico de minerales de valor simbólico como la turquesa, proveniente de la fuente de Inca Viejo. Este tipo de vínculo entre recursos minerales y tráfico caravanero también fue distinguido en otras áreas andinas (e.g. Garrido 2015; Núñez 1999). 
Los procesos de interacción se habrían acentuado en contextos prehispánicos tardíos e incas (e.g. Martel 2010; Núñez 1999), lo cual concuerda con la cronología de las ocupaciones humanas de la cueva (ver más adelante). La circulación de iconografías y temáticas compartidas constituye un indicador fundamental del traspaso de información en escala amplia.

En este trabajo, se caracterizan y analizan las representaciones rupestres de Cueva Inca Viejo y se realiza un estudio comparativo macrorregional de los patrones y temáticas de las iconografías relevadas en el sitio, como aporte a la discusión de los procesos mencionados previamente. Estos análisis no solo permiten abordar procesos de interacción y transmisión de información cultural, sino también realizar una aproximación a la cronología relativa de este registro. Al mismo tiempo, los estudios comparativos y cronológicos de las pinturas rupestres examinadas contribuyen a la discusión de las continuidades y los cambios ocurridos a partir de la expansión del Imperio inca en la región en el marco de las actividades minero-rituales. Finalmente, se enfatiza que la caracterización del arte rupestre de Cueva Inca Viejo desarrollada aquí implica un estudio integral del conjunto pictórico, tanto descriptivo y cuantitativo de las representaciones como a través de los análisis físico-químicos realizados hasta el momento, dirigidos a explorar la naturaleza de los elementos pigmentantes.

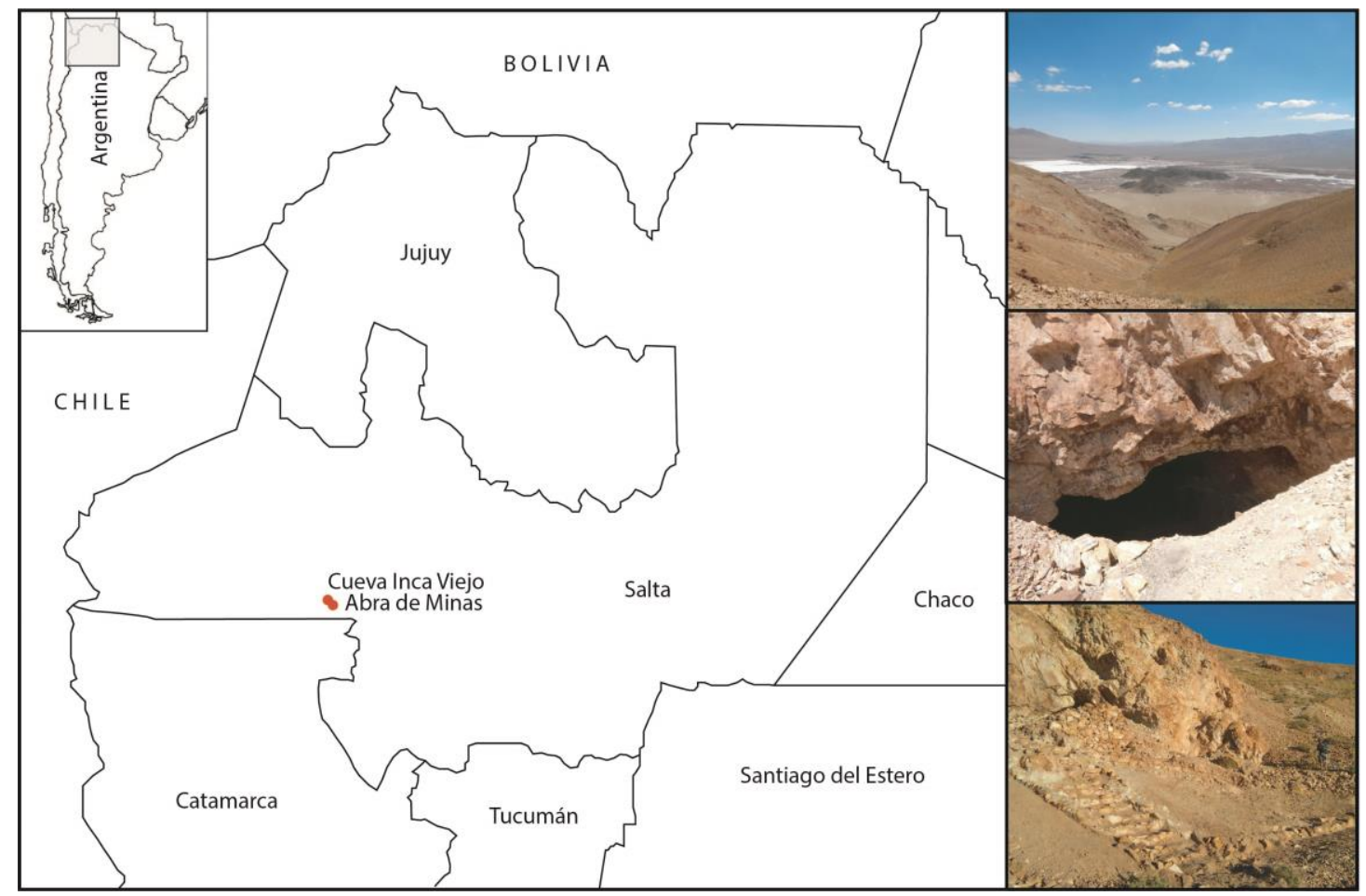

Figura 1. Localización de los sitios Cueva Inca Viejo y Abra de Minas. Referencia de las imágenes a la derecha. Superior: Vista del salar de Ratones desde el sitio. Centro: Boca de entrada de la cueva. Inferior: Estructura ceremonial con escalera en el talud de ingreso. 


\section{El sitio Cueva Inca Viejo}

A partir del año 2009, se iniciaron los estudios sistemáticos en la cuenca de Ratones y particularmente en Cueva Inca Viejo (López et al. 2009, 2015). A dos km al este del sitio, se encuentra Abra de Minas, un asentamiento conformado por 92 estructuras arquitectónicas que denota una intensa ocupación incaica (López y Coloca 2015). En el caso de Cueva Inca Viejo, el impacto del Tawantinsuyu es notable tanto en su interior como en sus alrededores. Se trata de un sitio arqueológico ubicado a $4312 \mathrm{~m}$ s.n.m., con una boca de entrada de 6,3 $\mathrm{m}$ de ancho y más de $13 \mathrm{~m}$ de fondo en la cámara principal (Figura 2; López et al. 2015). Se localiza en la ladera occidental del cerro Inca Viejo, intensamente modificado por los incas a partir de la construcción de un camino amurallado de más de $200 \mathrm{~m}$ de longitud que llega hasta la base de entrada a la cueva. Esta alta intensidad de trabajo se explica ante todo por la presencia de la fuente de mineral turquesa en el cerro y en la cueva (López et al. 2018). Este mineral fue sumamente valorado por las poblaciones andinas prehispánicas y especialmente por las elites incas de Cusco, Perú, en el centro del Imperio. Se trata de la primera fuente de turquesa estudiada con evidencia de explotación prehispánica en el Noroeste argentino (López et al. 2018). Cabe señalar que varias de las pinturas rupestres de la cueva se realizaron sobre paredes que registran trabajo minero previo (López et al. 2018, 2020).

Entre las características generales del sitio, sobresale material arqueológico vinculado con diversas prácticas rituales (López et al. 2020). En especial, se puede mencionar la presencia de ofrendas con envolturas de gramíneas, semillas como el cebil (alucinógeno utilizado en celebraciones rituales), huesos de camélidos y plumas de aves exóticas (Araya 2017; López et al. 2015; Seguí 2019). Una de estas ofrendas fue registrada en la entrada de una de las aberturas mineras y su fechado coincide con el Período Inca (ver Tabla 1). En otros contextos andinos, se ha planteado la importancia de la depositación de ofrendas en la entrada de socavones, indicando el vínculo entre minería y ritualidad (Platt et al. 2006). En este caso, resulta singular la alta frecuencia de plumas $(n=1076)$, en su mayoría procedentes de lugares lejanos como las yungas (Seguí 2019). Las plumas exóticas corresponden a diversas especies de psitácidos de colores llamativos. No puede dejar de mencionarse que además de la asociación con los ingresos a socavones, las ofrendas con plumas se encuentran en las cercanías de los paneles de arte rupestre más destacados de la cueva (al norte) (Figura 2). En este espacio también se hallaron las semillas de cebil $(n=4)$, las cuales podrían vincularse con un posible uso en rituales de producción minera del culto al otorongo (Coloca y López 2021). Al respecto, se debe considerar que en el mismo sector se encuentra la imagen rupestre de un jaguar (ver más adelante). Además, se hallaron semillas de algarrobo y chañar, y marlos y granos de maíz. En algunos casos, se pudo determinar el procesamiento para la obtención de bebidas, generalmente usadas en ceremonias o rituales en contextos mineros (Araya 2017). Las bebidas alcohólicas más comunes utilizadas en estas celebraciones andinas fueron la chicha y la aloja. Se subraya la 
presencia, tanto en este sitio como en Abra de Minas, de fragmentos de aríbalos incas, cuya función principal se asignó a la preparación de estas bebidas. Todo el conjunto sugiere un contexto ritual vinculado con la minería. Estos atributos han permitido señalar a la cueva como una huaca minera (López et al. 2018). A su vez, el valor minero/simbólico de este contexto se completa con la recuperación de numerosos fragmentos minerales de color celeste verdoso $(n=1996)$, que corresponderían mayoritariamente a turquesa (López et al. 2018, 2020). A estos indicadores, debe sumarse la presencia de pusno (material semidigerido procedente del estómago de los camélidos) sobre las paredes de la cueva, interpretado como una ofrenda a la huaca minera (Coloca y López 2021).

\begin{tabular}{|c|c|c|c|c|c|}
\hline $\begin{array}{c}\text { Sitio/Unidad de } \\
\text { excavación/Capa }\end{array}$ & Laboratorio & Fecha AP & $\begin{array}{c}\text { Fecha } \\
\text { calibrada DC, } \\
\mathbf{1} \text { sigma }\end{array}$ & $\mathbf{\delta 1 3 C}$ & Muestra \\
\hline $\begin{array}{c}\text { Cueva Inca Viejo } \\
\text { Sondeo 2, capa A }\end{array}$ & LP-3503 & $1390 \pm 70$ & $641-766$ & -20 & Óseo (camélido) \\
\hline $\begin{array}{c}\text { Cueva Inca Viejo } \\
\text { Sondeo 9, capa A }\end{array}$ & LP-3491 & $1120 \pm 50$ & $897-1020$ & -20 & Óseo (camélido) \\
\hline $\begin{array}{c}\text { Cueva Inca Viejo } \\
\text { Sondeo 2, capa B }\end{array}$ & LP-2909 & $860 \pm 60$ & $1179-1273$ & -20 & Óseo (camélido) \\
\hline $\begin{array}{c}\text { Cueva Inca Viejo } \\
\text { Sondeo 7, capa A }\end{array}$ & LP-3489 & $430 \pm 50$ & $1446-1619$ & -25 & Gramíneas \\
\hline
\end{tabular}

Tabla 1. Fechados radiocarbónicos del sitio Cueva Inca Viejo.

Además de la evidencia mencionada, en la campaña de 2017, se descubrió una estructura ceremonial incaica en el talud formado al pie de la cueva (Figura 1; López et al. 2018). Dicha estructura está compuesta por un muro superior que obstaculiza la visión de la boca de entrada de la cueva, una plataforma rectangular adosada por delante de este muro, una escalera lateral con muros dobles a ambos lados, un recinto central y un muro inferior de más de $10 \mathrm{~m}$ de largo (López et al. 2020). Salvo el muro superior, el resto de la estructura estaba cubierto por las rocas y el sedimento que conformaban el talud de ingreso a la cueva. En los trabajos de remoción y descubrimiento de sus distintas partes, se recuperaron dos monolitos incaicos, similares a algunos objetos hallados en Cusco y en otros sectores del Imperio; estos artefactos han sido usados en ceremonias de libación y ofrendas de culto a los ancestros y deidades notables (López y Coloca 2019). El registro descrito ha llevado a definir a esta estructura como un ushnu (López et al. 2018, 2020). El término ushnu remite a espacios y estructuras arquitectónicas de uso ceremonial por parte de los incas para la realización de ofrendas y libaciones (Zuidema 2014). Dentro de la variabilidad arquitectónica de los ushnus, se reconocen plataformas rectangulares, cuadrangulares o trapezoidales con uno o más niveles $\mathrm{y}$, en algunos casos, con escalinatas o rampas (Monteverde Sotil 2011). 
En Cueva Inca Viejo, también se han detectado indicadores relacionados con el caravaneo, tanto en el arte rupestre (camélidos alineados y guiados por un antropomorfo) como por las diversas sogas anudadas recuperadas en excavación, posiblemente vinculadas con el atalaje de los camélidos (López et al. 2015). Al respecto, debe señalarse la alta frecuencia de elementos exóticos procedentes de la puna y de los valles mesotermales y las yungas. Se trata de bienes y recursos transportados desde largas distancias, para lo cual el tráfico caravanero habría sido muy importante. Entre ellos, se puede mencionar la presencia de obsidianas de fuentes tales como Zapaleri, a más de $300 \mathrm{~km}$; semillas y frutos desde los valles como maíz, zapallo, algarrobo y chañar; y materiales de las yungas como las semillas de cebil y las plumas de los psitácidos (Araya 2017; López 2020; Seguí 2019).

En diferentes sectores del interior de la cueva se realizaron 16 sondeos de 0,5 x $0,5 \mathrm{~m}$ y una cuadrícula de $1 \times 1 \times$ arqueosedimentaria y obtener material para datar (ver López et al. 2020). Desde el punto de vista estratigráfico, no se han podido definir componentes distintos debido a la intensa modificación producida por la ocupación inca. Prueba de ello es la instalación de la estructura ceremonial en la entrada de la cueva. Sin embargo, se han obtenido fechados radiocarbónicos que indican la presencia humana prehispánica en el sitio desde ca. 650 DC hasta contextos incaicos (ver Tabla 1). Más allá de la intensa ocupación Inca, no puede soslayarse el hecho de que la cueva presenta registro antrópico previo, fundamentalmente de contextos tardíos preincaicos. En este escenario, el estudio del arte rupestre aporta información significativa a la discusión sobre este tema.

\section{Aspectos metodológicos aplicados en el estudio de las representaciones rupestres de Cueva Inca Viejo}

Se consideró a las representaciones individuales como las unidades mínimas de análisis (Aschero y Martel 2005; Muscio 2006). Las mismas se cuantificaron y fueron clasificadas en tres grandes grupos: figurativas, no figurativas e indeterminadas (Fiore 2011). Dentro de las figurativas, se distinguieron camélidos, ornitomorfos, felinos, zooantropomorfos, zoomorfos indeterminados, antropomorfos y objetos. Entre las no figurativas, se reconocieron formas geométricas. En el conjunto de las indeterminadas, se incluyeron aquellas que no pudieron ser asignadas a alguno de los dos grupos anteriores, principalmente debido al nivel de deterioro natural de las pinturas.

Como parte de la caracterización y análisis de las pinturas rupestres del sitio, también se realizaron estudios mediante microscopio electrónico de barrido con analizador EDX (MEB-EDX) para determinar los elementos químicos presentes en dos pigmentos rojizos de capa y en un fragmento de pintura negra relevada en uno de los paneles. Ambos colores -rojo y negro- han sido los únicos registrados en el arte rupestre de Cueva Inca Viejo. 
La descripción general de las distintas representaciones se realizó según las características morfológicas y los temas recurrentes. Entre las temáticas más comunes en la cueva se encuentran las caravanas de llamas (para el análisis de este tema ver Aschero 2000, 2007; Berenguer 1999; Martel 2010, 2011; Podestá y Olivera 2006; entre otros). Asimismo, se relevaron motivos de amplia replicación andina como los antropomorfos con brazos alzados y las imágenes felínicas (en especial de jaguar), los cuales han sido relacionados con espacios mineros, entre otros contextos (e.g. Bousse-Cassagne 2005; San Francisco y Ballester 2010). Los análisis descriptivos se desarrollaron a partir de fotografías tomadas in situ y por medio de programas de amplio uso en el estudio del arte rupestre como ImagenJ - complemento DStretch, un software para el mejoramiento y manipulación de imágenes. Como parte del registro gráfico, se hicieron calcos digitales empleando de forma combinada Adobe Photoshop y Adobe Illustrator.

Finalmente, se procedió a establecer una comparación macrorregional de las representaciones de Cueva Inca Viejo con otras iconografías similares de diversos contextos de los Andes centro-sur, específicamente en el Noroeste argentino y en el Norte de Chile. Este estudio se realizó a partir de patrones y temáticas recurrentes entre los motivos observados en la cueva y aquellos descritos en otras áreas andinas, a través de información bibliográfica. Al mismo tiempo, se realizó una caracterización morfológica comparativa para el abordaje de los patrones de diseño correspondientes a las representaciones predominantes.

La inserción de estos estudios en una escala espacial amplia posibilitó realizar una aproximación a la cronología relativa de las diversas representaciones de Cueva Inca Viejo. La discusión cronológica se basó en la recurrencia de algunos patrones de diseño y en ciertas temáticas distintivas de determinados períodos. Este abordaje constituyó también un punto de partida para discutir procesos de interacción macrorregional y transmisión de información cultural a lo largo de los Andes centro-sur.

\section{Las pinturas rupestres en Cueva Inca Viejo: Características generales y determinaciones físico-químicas}

El arte rupestre de Cueva Inca Viejo se distribuye en 7 paneles localizados en distintos sectores de la cámara principal de la cueva: noroeste (paneles 1, 2, 3 y 4), noreste (panel 5), sudeste (panel 6) y sudoeste (panel 7) (Figura 2). Como soporte, se utilizaron las paredes de la cueva cuya roca de caja es una dacita porfírica (López et al. 2015 , 2018). Los procesos naturales actuantes sobre la roca de la cueva han producido una fuerte meteorización superficial incidiendo sobre las pinturas, algunas de las cuales se encuentran bastante deterioradas. La mayor parte de las pinturas se ubica en las paredes del sector noroeste (cuatro paneles), en un costado de la boca de entrada de la cueva y en el ingreso a una de las galerías secundarias abierta antrópicamente (Figura 2). Al respecto, es importante señalar que todas las manifestaciones rupestres del sector noroeste fueron realizadas sobre paredes cortadas y trabajadas previamente por prácticas mineras prehispánicas. Esta característica del sector, sumada al hallazgo 
de una envoltura de gramíneas compuesta por distintos materiales arqueológicos e interpretada como una ofrenda fechada en el Período Inca (ver Tabla 1), prueba la asociación entre las prácticas mineras, el arte rupestre y la ritualidad (López et al. 2018, 2020).

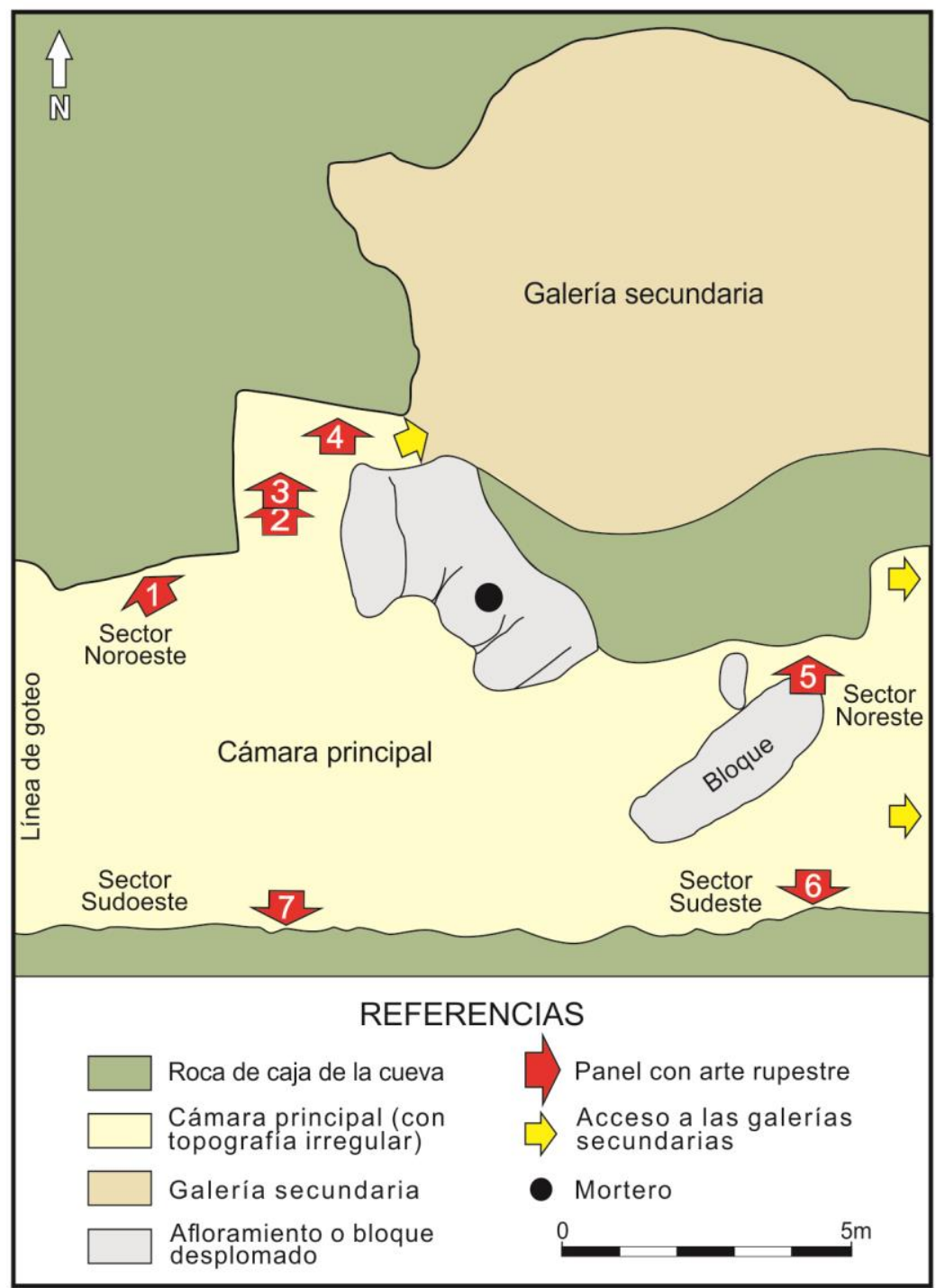

Figura 2. Planta de Cueva Inca Viejo con la localización de los sectores y paneles con arte rupestre.

Los motivos más frecuentes son los zoomorfos y antropomorfos y, en menor medida, los geométricos. En la distinción general en grupos, se observa un alto porcentaje de representaciones figurativas $(76,8 \%)$ por sobre las no figurativas $(6,4 \%)$ y un número apreciable de indeterminadas (16,8 \%). En las figurativas, prevalecen las zoomorfas (43,2 \%), mientras que las antropomorfas o antropomorfizadas constituyen el $16,8 \%$. Dentro de estas últimas, se incluyeron formas tipo "unku, escutiforme o personificaciones de hachas". Se trata de morfologías con sus lados mayores curvados hacia el interior, en adelante, denominadas de manera genérica como "figuras de lados cóncavos" (ver caracterizaciones similares en López Campeny y Martel 2014; Montt y 
Pimentel 2009; Troncoso 2011). Entre los motivos de zoomorfos, dominan los camélidos $(37,3 \%)$, aunque además se reconocen felinos, ornitomorfos y otros zoomorfos indeterminados (Tabla 2). Asimismo, se evidencian diversos motivos de objetos como trompetas, hachas y lazos (14,6 \%). La mayoría de ellos se asocia con las figuras antropomorfas o zoomorfas. Las representaciones geométricas son menos frecuentes (e.g. círculos bicolores en negro y rojo-anaranjado) (Tabla 2).

\begin{tabular}{|c|c|c|c|c|}
\hline \multicolumn{3}{|c|}{ Representaciones } & Frecuencia & $\%$ \\
\hline \multirow{8}{*}{ Figurativas } & \multirow[b]{2}{*}{ Antropomorfos } & Figuras humanas & 27 & 14,6 \\
\hline & & $\begin{array}{c}\text { Unkus - Escutiformes - } \\
\text { Personificaciones de hachas }\left(^{*}\right)\end{array}$ & 4 & 2,2 \\
\hline & \multicolumn{2}{|c|}{ Zooantropomorfos } & 4 & 2,2 \\
\hline & \multirow{4}{*}{ Zoomorfos } & Camélidos & 69 & 37,3 \\
\hline & & Felinos & 3 & 1,6 \\
\hline & & Suri & 1 & 0,5 \\
\hline & & Otros indeterminados & 7 & 3,8 \\
\hline & \multicolumn{2}{|l|}{ Objetos } & 27 & 14,6 \\
\hline \multirow{4}{*}{$\begin{array}{l}\text { No } \\
\text { figurativas }\end{array}$} & \multirow{4}{*}{ Geométricos } & Círculos & 8 & 4,3 \\
\hline & & Líneas & 1 & 0,5 \\
\hline & & Puntos & 2 & 1,1 \\
\hline & & Triángulos & 1 & 0,5 \\
\hline \multicolumn{3}{|c|}{ Indeterminadas } & 31 & 16,8 \\
\hline \multicolumn{3}{|c|}{ TOTAL } & 185 & 100 \\
\hline
\end{tabular}

Tabla 2. Cuantificación de las representaciones rupestres en Cueva Inca Viejo.

$(*)$ En este trabajo, estas figuras han sido denominadas genéricamente como "figuras de lados cóncavos".

Las pinturas rupestres de Cueva Inca Viejo fueron realizadas en color negro (predominante) y rojo-anaranjado. Para establecer la composición de los materiales pigmentantes, las investigaciones sobre arte rupestre que incluyen pictografías requieren de un número apreciable de análisis físico-químicos. Estos estudios permiten distinguir técnicas de preparación de las pinturas, algunas destinadas a transformar los colores naturales, aunque la mayoría de las veces son útiles para discriminar componentes inorgánicos y orgánicos, mezclas utilizadas para mejorar la aplicabilidad de las pinturas incidiendo favorablemente sobre su plasticidad, adherencia al soporte y durabilidad.

En la actualidad, se cuenta con tres determinaciones físico-químicas (EDX) correspondientes a dos pigmentos rojos de capa y a una pintura negra sobre pared. Los microanálisis de los dos pigmentos y de la pintura fueron realizados con el Microscopio Electrónico de Barrido FEI Quanta 200 provisto de un Analizador EDAX DX-4 (MEB-EDX) en el Centro Atómico Constituyentes (CNEA). Los materiales analizados son dos agregados -pequeñas "bolitas" de color rojo-anaranjado- de consistencia pastosa y altamente pigmentantes; estos compuestos inorgánicos fueron 
recuperados en capa en un sector cercano al panel 1 con pinturas rojas. La otra muestra estudiada es un microfragmento de pintura negra obtenido de la figura de un camélido del sector noroeste de la cueva (Tabla 3).

\begin{tabular}{|c|c|c|c|}
\hline Muestra & Descripción & Color Munsell & Procedencia \\
\hline MB1 & Pigmento rojo & 10R 4/8 (Red) & $\begin{array}{c}\text { Cueva Inca Viejo, cuadrícula 1 - } \\
\text { capa A }\end{array}$ \\
\hline MB2 & Pigmento rojo & $2,5 Y R 4 / 8($ Red $)$ & $\begin{array}{c}\text { Cueva Inca Viejo, cuadrícula 1 - } \\
\text { capa A }\end{array}$ \\
\hline MA & Pintura negra & $\begin{array}{c}\text { GLEY 1 2,5/N } \\
\text { (Black) }\end{array}$ & $\begin{array}{c}\text { Cueva Inca Viejo, Panel 4, sector } \\
\text { Noroeste - pared }\end{array}$ \\
\hline
\end{tabular}

Tabla 3. Los pigmentos rojos y la pintura negra recuperados en Cueva Inca Viejo.

Los resultados EDX indican niveles elevados de carbono $(\mathrm{C})$ en la pintura negra y de hierro ( $\mathrm{Fe}$ ) en los pigmentos rojizos; se registraron también valores relativamente bajos, pero significativos, de los elementos azufre (S) y calcio (Ca) en las tres muestras analizadas, además de variadas proporciones de otros componentes (Tabla 4). Se señala que en dicha tabla no se incluyó el elemento oxígeno $(\mathrm{O})$, mayoritario en los materiales analizados, para poner de relieve los elementos distintivos.

\begin{tabular}{|c|c|c|c|c|c|c|c|c|c|c|c|c|}
\hline Muestra & $\mathbf{C}$ & $\mathbf{N a}$ & $\mathbf{M g}$ & $\mathbf{A l}$ & $\mathbf{S i}$ & $\mathbf{P}$ & $\mathbf{S}$ & $\mathbf{C l}$ & $\mathbf{K}$ & $\mathbf{C a}$ & $\mathbf{T i}$ & $\mathbf{F e}$ \\
\hline MB1 & 16,2 & 1,7 & 1,4 & 9,7 & 18,1 & 1,0 & 10 & - & 5,2 & 4,4 & - & 32,4 \\
\hline MB2 & 33,4 & 1,1 & - & 10 & 10,4 & 0,1 & 2,3 & - & 1,0 & 1,7 & - & 40,0 \\
\hline MA & 63,6 & 0,2 & 0,1 & 12,1 & 15,3 & 0,2 & 1,8 & 0,3 & 1,1 & 3,1 & - & 2,3 \\
\hline $\begin{array}{l}\text { Roca }\left(^{*}\right) \\
\text { (dacita) }\end{array}$ & - & 1,1 & 1,5 & 29,9 & 57,1 & - & - & - & 1,2 & 1,9 & 0,3 & 6,9 \\
\hline
\end{tabular}

Tabla 4. Composición elemental (\% en peso) de los pigmentos rojos y la pintura negra (EDX). Los porcentajes indicados corresponden al promedio de tres mediciones en cada muestra. $\left({ }^{*}\right.$ Composición elemental de la roca de caja de la cueva, los valores fueron aproximados a un decimal (Tomado de López et al. 2018).

En las muestras pigmentantes rojizas, además del hierro, elemento cromóforo que otorga el color al material, se detectaron otros elementos que serían compatibles con materiales arcillosos, entre ellos, aluminio $(\mathrm{Al})$, silicio $(\mathrm{Si})$, potasio $(\mathrm{K})$, sodio $(\mathrm{Na})$ y magnesio (Mg) (Tabla 4). Aunque los porcentajes son relativamente bajos y los niveles de hierro no son extremadamente altos, se sugiere que podría tratarse de una mezcla pigmentaria de base arcillosa con moderada participación de hierro (Fe III), pudiendo ser este un elemento más en la estructura cristalina de la arcilla o ser un constituyente esencial de los óxidos y oxihidróxidos férricos (¿goethita y/o hematita?), posiblemente combinados con los materiales arcillosos. Los tenores de $\mathrm{S}$ y $\mathrm{Ca}$, si bien son un tanto bajos, estarían denotando la presencia de yeso o anhidrita, minerales habitualmente utilizados como carga (extenders) en las pinturas rupestres, el sostén de los pigmentos. Por último, el contenido de C podría vincularse con los carbonatos que, por lo general, 
son parte de los depósitos evaporíticos del área, además de otras sales (Hongn y Seggiaro 2001). Futuras investigaciones permitirán establecer la composición de los minerales involucrados.

La pintura negra, en cambio, tiene alto nivel de carbono (C) y variadas proporciones de otros elementos, entre ellos, $\mathrm{S}$ y Ca que, aun siendo bajas, sugieren la participación de anhidrita o yeso, posiblemente utilizados como carga. El resto de los elementos registrados son acordes con los valores hallados en la roca de caja, así como también el Fe (ver Tabla 4). Es preciso señalar que al extraer la muestra de pintura negra se desprendió una pequeña porción superficial de la roca soporte, cuya composición podría estar incidiendo en las determinaciones por EDX. La presencia de cloro $(\mathrm{Cl})$ en la pintura negra sería indicativa de contaminación ambiental.

El exiguo contenido de fósforo $(\mathrm{P})$ determinado en las tres muestras es de origen incierto, aun siendo el cerro portador de turquesa, un fosfato hidratado de $\mathrm{Al}$ y Cu (López et al. 2018). La turquesa del cerro Inca Viejo cristalizó en las cavidades e intersticios del cuerpo rocoso como también tapizando diaclasas y rellenando fisuras que generaron venillas y vetas que cruzan la roca siguiendo múltiples direcciones. Estas características explican la ausencia de fósforo y cobre, dos de los tres elementos diagnósticos del mineral turquesa, en el fragmento de roca analizado por EDX (Tabla 4). En consecuencia, ese porcentaje de fósforo medido en los pigmentos rojos y en la pintura negra parece ser indicativo de contaminación antrópica, por ejemplo, si los morteros y manos de moler utilizados en la preparación de las pinturas también fueron empleados en otras actividades, como podría ser la partición de huesos (ver Yacobaccio et al. 2012).

Otro tema a considerar en este estudio, es el aspecto que presentan las superficies sobre las que fueron pintados algunos de los paneles (principalmente el panel 1); en varias de las imágenes, las pinturas fueron plasmadas sobre un material blancuzco (Color Munsell: 2,5Y 9,5/1 White). Dicho material parece ser de composición arcillosa (probablemente, asociado con otros componentes) y se encuentra en el cerro formando vetas (¿estériles?) de dimensiones y rumbos diversos, sobre las que de manera aleatoria se pintaron algunas de las representaciones (Figura 4). Este rasgo, merecedor de investigaciones adicionales, estaría relacionado con la naturaleza del stock dacítico mineralizado vinculado con los sistemas geotermales que dieron origen al depósito mineral (Chabert 1999).

En síntesis, es factible que los materiales pigmentantes rojizos descartados hubiesen estado listos para pintar, teniendo en cuenta la detección de elementos indicadores de sulfatos de calcio. No se puede precisar si estos materiales "preparados" estuvieron destinados a la producción de pinturas rupestres y, aunque su uso en arte es poco conveniente debido a las propiedades intrínsecas de los materiales arcillosos (ver Solá et al. 2013), tampoco se puede descartar su empleo. Por otra parte, el porcentaje de carbono registrado en la pintura negra sugiere que 
probablemente el pigmento utilizado hubiese sido carbón de origen orgánico, muy común en la realización de este tipo de manifestaciones rupestres. Estos primeros resultados permiten plantear el uso de yeso (o anhidrita) como carga de las pinturas; no obstante, es indispensable determinar los minerales involucrados y los materiales utilizados como ligantes (binders) por lo que se requiere avanzar en las investigaciones mediante la utilización de técnicas físico-químicas complementarias.

\section{Descripción de las representaciones rupestres}

La descripción del arte rupestre se desarrolla a partir de las temáticas más comunes registradas en Cueva Inca Viejo, las cuales incluyen los camélidos alineados, atados y guiados por un antropomorfo (temática caravanera), el antropomorfo con los brazos alzados en sección U o V con portación o asociación de objetos y/o zoomorfos, camélidos en actitud dinámica y en cópula en interacción con antropomorfos, figuras de lados cóncavos tipo "unkus, escutiformes o personificaciones de hachas" y, por último, antropomorfos en actitud dinámica con objetos como trompetas y posibles hachas o escudos relacionados, en algunos casos, con lo bélico o el conflicto (López et al. 2015). Además, se registraron círculos concéntricos bicolores, un suri y el jaguar mencionado en secciones previas.

La distribución de temáticas en cada sector refleja ciertas regularidades pero también algunas variaciones. En el sector noroeste (paneles 1 y 4), se encuentran representados dos de los temas más relevantes, el caravaneo y el antropomorfo con los brazos alzados. Asimismo, en este sector se evidencian camélidos en actitud dinámica y en cópula (panel 4), figuras de lados cóncavos (paneles 2, 3 y 4) y dibujos geométricos (e.g. círculos) (panel 1). En el sector noreste (panel 5), se reconoce únicamente una caravana de llamas guiada por un antropomorfo. En el sector sudeste (panel 6) se distinguen motivos vinculados con el conflicto (e.g. los antropomorfos con trompetas). Por último, en el sector sudoeste (panel 7), se detecta una caravana de llamas apenas discernible por el deterioro de la pintura, por lo cual, no se hará hincapié en su descripción.

En relación con la temática caravanera, se observan similitudes y diferencias en las distintas representaciones de los camélidos. En el sector noroeste, se distinguen dos caravanas con características compartidas, denominadas a los fines descriptivos como A y B (Figura 3 a y 3b). Se evidencian camélidos alineados, atados y guiados por un antropomorfo. Sin embargo, se aprecian algunas diferencias en los patrones de los camélidos. En la caravana A (panel 1, en la entrada de la cueva), los camélidos son más esquemáticos que los de la caravana $B$ (panel 4, en el sector de ingreso a la galería secundaria norte). En este último caso, se trata de camélidos naturalistas, tanto en la morfología como en las proporciones de sus partes. Otra particularidad de esta caravana es la presencia de llamas de cuatro patas, lo cual contrasta con la morfología del resto de los camélidos atados y en fila en Cueva Inca Viejo. Aun cuando en la proximidad de las caravanas se encuentran figuras de antropomorfos con los brazos alzados, por 
el momento, no puede realizarse una asociación temática entre ambos motivos. De todas maneras, no se descarta una resignificación más tardía de estos personajes en relación con la temática caravanera (López et al. 2015).
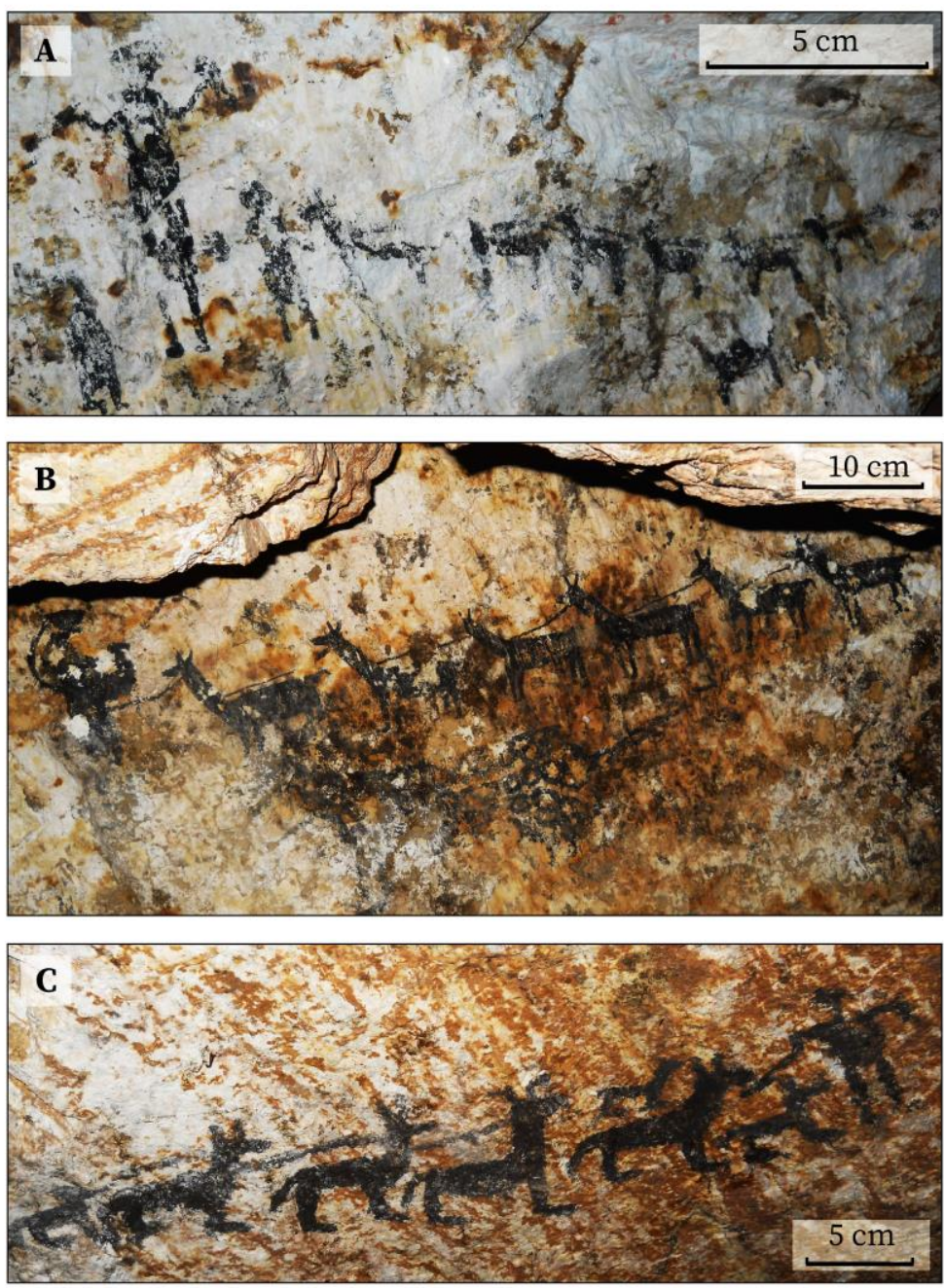

Figura 3. Caravanas de camélidos reproducidas en Cueva Inca Viejo.

Cerca de la caravana A, se observa la imagen de un camélido con carga (Figura 3a), mientras que en la parte inferior de la caravana B, se reconoce la figura del jaguar (Figura 3b). Estas dos caravanas comparten rasgos con otra ubicada en el sector noreste (panel 5). Sin embargo, el patrón morfológico y las proporciones exageradas de pies, cola y orejas de los camélidos distinguen la caravana de este sector (denominada C) de las descritas previamente (Figura 3c). Si bien la temática es la misma, las particularidades son distintivas. Entre ellas, se deben remarcar la extensión de los pies de los camélidos, el tamaño desproporcionado de las orejas en relación con el resto del cuerpo y las colas largas. 
Otro tema recurrente se vincula con el antropomorfo de los brazos alzados (Aschero 2000, 2007; Gallardo et al. 2012; González 2004; Horta 2004; López Oliva 2007; Pérez Gollán 1986; San Francisco y Ballester 2010; entre otros). Se trata de un personaje de amplia replicación a lo largo de los Andes, aunque con variantes propias (e.g. Aschero 2007; Horta 2004). En el panel 1, se registran al menos tres representaciones de este personaje (Figura $4 \mathrm{a}, 4 \mathrm{~b}$ y $4 \mathrm{c}$ ). Todas tienen los brazos flexionados hacia arriba en forma de $\mathrm{U}$ o $\mathrm{V}$ como así también la portación de objetos (e.g. hachas). A pesar de que el deterioro de las pinturas impide caracterizar plenamente las figuras, entre otros elementos, se observa la presencia de faldellín (e.g. antropomorfo A) (Figura 4a). En un caso, también se distingue una cabeza felínica, con fauces y orejas marcadas, tipo mascariforme (antropomorfo B) (Figura 4b). En otra figura, se detecta un objeto que se proyecta desde el codo, interpretado en otros contextos como una abstracción de cabeza cercenada (antropomorfo C) (Figura 4c).
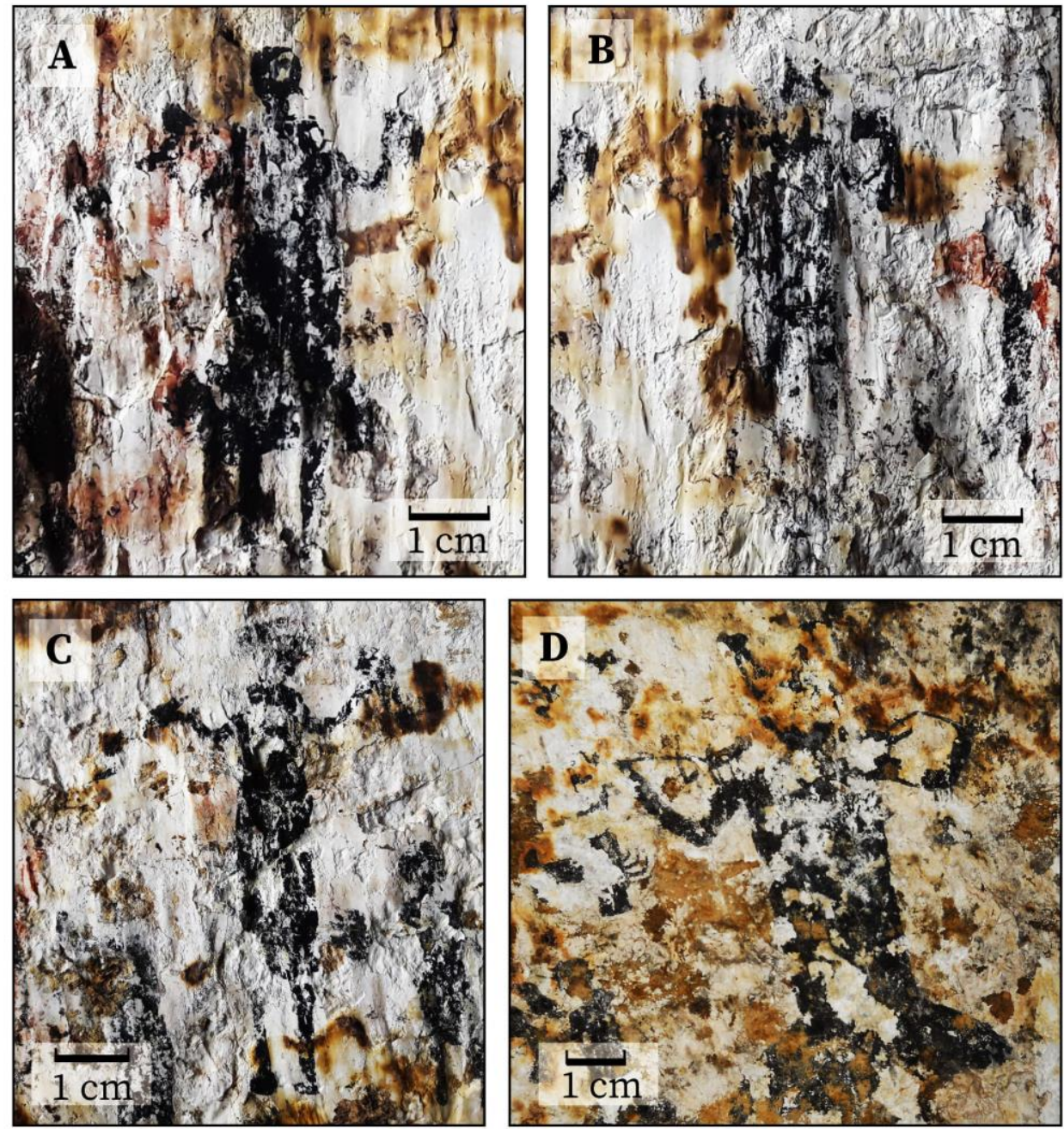

Figura 4. Los antropomorfos con los brazos alzados. 
Además de estas tres figuras, en el panel 4, hay otro motivo similar donde se localiza la caravana de llamas naturalistas (Figura 4d). Este antropomorfo con los brazos alzados sobresale por su mayor tamaño en relación con el resto de los personajes y por ciertas particularidades como dos felinos simétricos en sus hombros, unidos a cada mano por líneas que podrían interpretarse como lazos (antropomorfo D). También presenta proyecciones cefálicas (cabeza radiada). A un costado, se localiza un hacha con plumas y en uno de sus codos se repite la proyección de un objeto que simbolizaría una cabeza cercenada. Esta figura también tiene faldellín como los otros antropomorfos de características compartidas. En términos generales, se reconoce una temática común entre estos motivos que podría relacionarse con deidades panandinas (González 2004; Horta 2004). A diferencia de estos antropomorfos, las figuras que guían las caravanas de llamas son más pequeñas, esquemáticas y sin atributos distintivos aunque ligadas a los camélidos (Figura 3a, 3b y 3c). Los primeros corresponderían a seres sobrenaturales vinculados con lo religioso, mientras que los últimos serían personajes terrenales, pastores que conducen las caravanas.

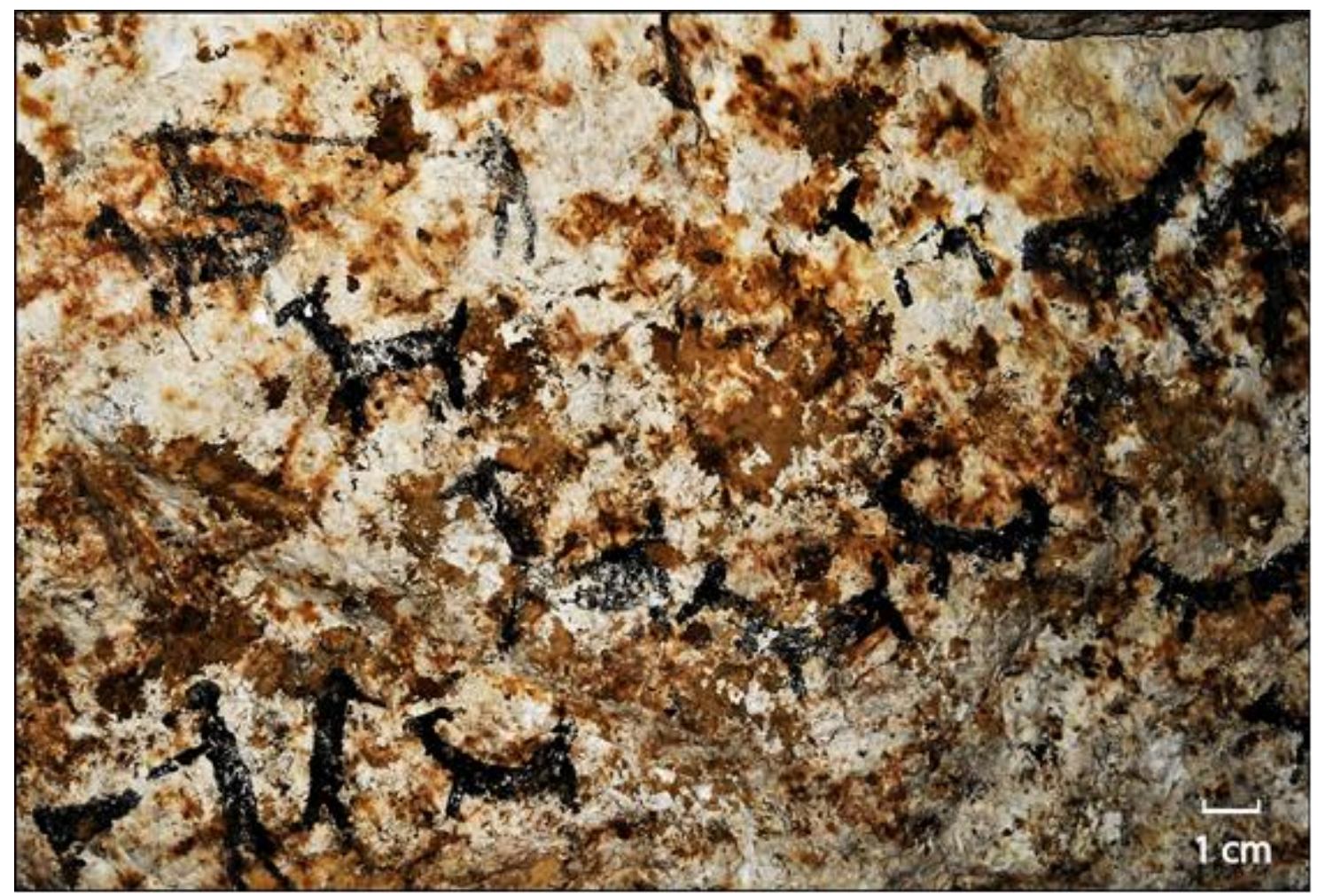

Figura 5. Camélidos en actitud dinámica. Véanse los camélidos en "cópula" en el sector superior izquierdo.

Los camélidos en actitud dinámica aludidos en párrafos anteriores (Figura 5) se encuentran principalmente en el panel 4 del sector noroeste, asociados con antropomorfos y una figura de lados cóncavos. Entre estos motivos, se distinguen dos representaciones de camélidos en cópula. Una de ellas tiene un antropomorfo 
enlazando a uno de los camélidos. Esta figura (bastante deteriorada) también se distingue por un camélido de cuatro patas de patrón más naturalista (sector superior izquierdo de la Figura 5). En cambio, el resto de los camélidos "dinámicos" del panel presenta un patrón esquemático con dos patas.

En los paneles del sector noroeste son recurrentes las figuras de lados cóncavos (Figura 6 A, B y C). Aun cuando podrían corresponder a unkus u otro tipo de vestimentas andinas, no se descarta como interpretación alternativa que se trate de escutiformes o personificaciones de hachas (e.g. Aschero 2000; Falchi et al. 2018; Ledesma 2012; López Campeny y Martel 2014; Montt y Pimentel 2009). Una de ellas se diferencia por su mayor tamaño y por el dibujo de dos atributos particulares: una posible cabeza y una diagonal doble en $\mathrm{X}$ en su interior apenas visible por el deterioro de la pintura (Figura 6A). Estas características indican que se trataría de una figura antropomorfizada de amplia recurrencia en los Andes (López Campeny y Martel 2014; Vilches y Uribe 1999).
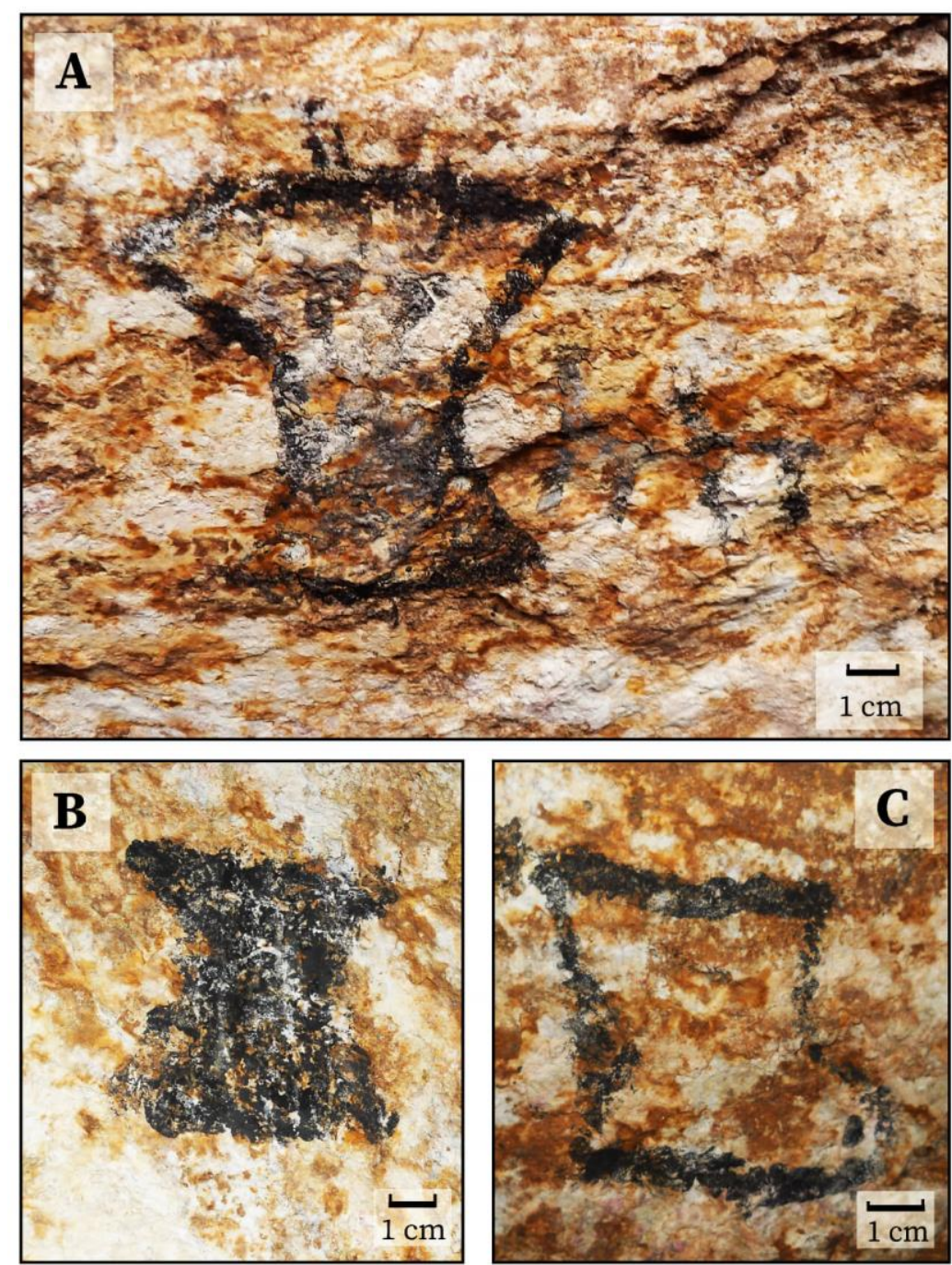

Figura 6. Figuras de lados cóncavos. 
Otra temática común reconocida en la cueva se vincula con los personajes portando objetos, como se observa en el sector sudeste. Se trata de antropomorfos en actitud dinámica con artefactos generalmente relacionados con lo bélico o el conflicto (Nielsen 2003). Entre los objetos, se distinguen trompetas y posibles hachas o escudos (Figura 7). Sin embargo, salvo las trompetas, el resto de los objetos puede interpretarse de manera diversa, dado el deterioro de las pinturas. Los tres personajes registrados tienen faldellín y están pintados en color negro (Figura 7). Dos de los antropomorfos corresponden a individuos sonando las trompetas que se proyectan desde sus cabezas, como si se tratara de un llamamiento o ritual vinculado con la guerra (Nielsen 2007).

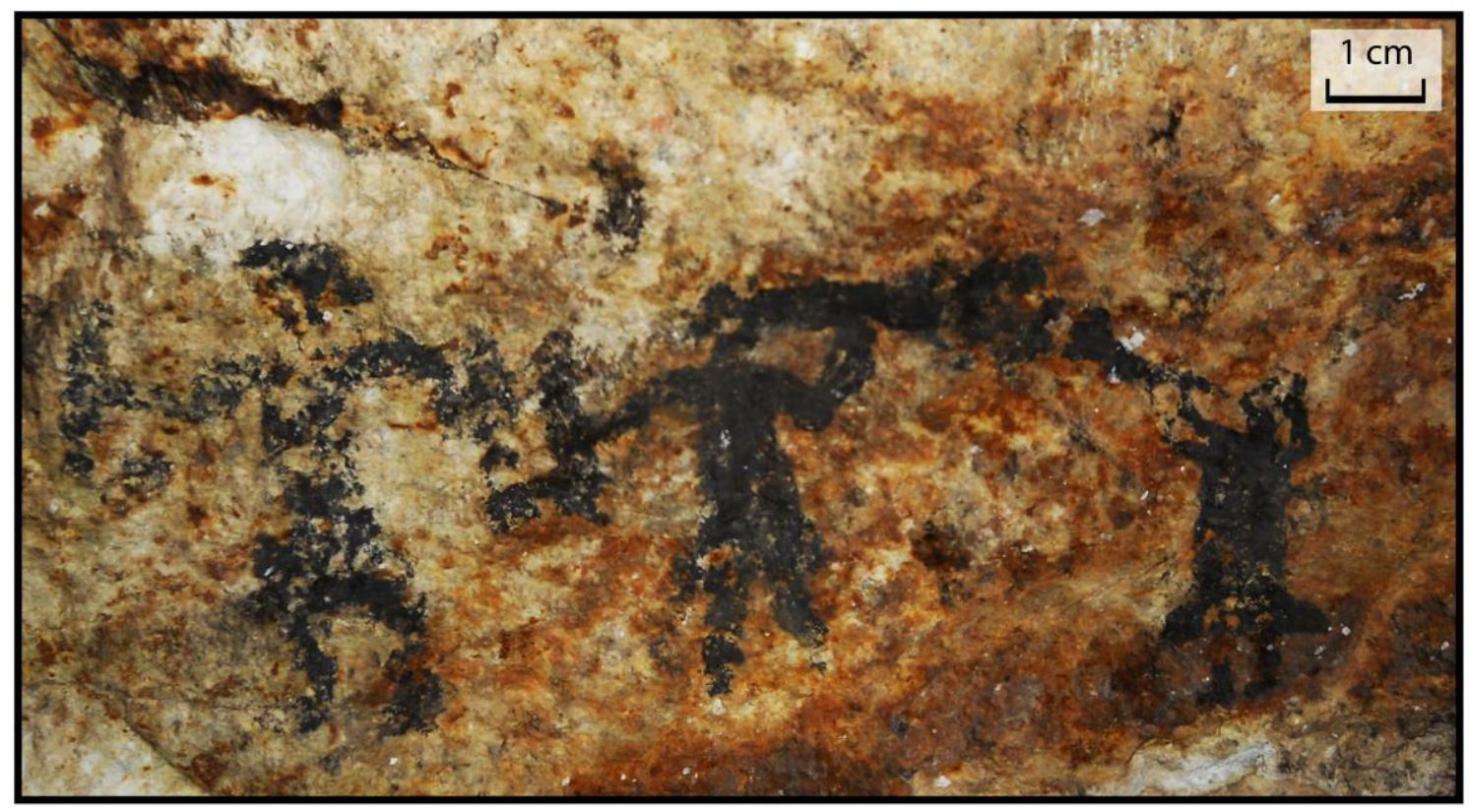

Figura 7. Antropomorfos con objetos relacionados con el conflicto (e.g. trompetas).

Asimismo, se debe puntualizar que en los paneles de la cueva hay otros tipos de representaciones. Entre ellas, se observan formas circulares de color negro y rojoanaranjado, localizadas en el panel 1 del sector noroeste en la entrada de Cueva Inca Viejo (Figura 8a y 8b). Es el único panel dónde se han registrado pinturas rojoanaranjadas en asociación con pinturas negras. En el resto de los paneles, exclusivamente se evidencian pinturas negras. Un detalle importante, referido a la temporalidad de las manifestaciones rupestres, es la superposición de un camélido de color negro sobre un camélido rojo. Esta característica constituye un indicador de la mayor antigüedad de las pinturas rojas de este panel. El hecho de que las figuras de este color se encuentren acotadas al sector de entrada de la cueva permitiría plantear una correspondencia cronológica más antigua de las mismas, dado que se trata de la primera pared trabajada antrópicamente con propósitos mineros en contextos prehispánicos. Posteriormente, se le superpusieron pinturas de color negro, quizás durante los períodos tardío/incaicos (ver más adelante discusión cronológica). En forma aislada, se detectan camélidos esquemáticos de dos patas y solamente uno más 
naturalista de cuatro patas. En este panel, también se localizan figuras de antropomorfos esquemáticos rojos. Uno de ellos tiene características particulares como la presencia de puntos en su interior y extensiones hacia los costados que no se distinguen claramente (¿representación de un ala en un antropomorfo-ave?). Dado el deterioro de la pintura no se puede profundizar en este aspecto. Un deterioro similar se observa en una figura triangular localizada por encima de la caravana B, lo cual impide avanzar en sus atributos particulares.

Finalmente, deben mencionarse dos motivos reproducidos una única vez, el suri y el jaguar (Figura 8c y 8d). En el caso del suri, se trata de una representación naturalista en el panel 1 del noroeste de la cueva. La pintura del jaguar (próxima a la caravana naturalista del panel 4), aunque muy deteriorada, permite distinguir el contorno del felino con patas, fauces, orejas y cola, y el detalle de las manchas circulares características de su pelaje (Figura 8d). Su ubicación en el sector de ingreso a la galería secundaria norte refuerza el posible vínculo de este motivo con la minería, teniendo en cuenta la importancia del culto al otorongo en estos contextos (Bouysse-Cassagne 2005).
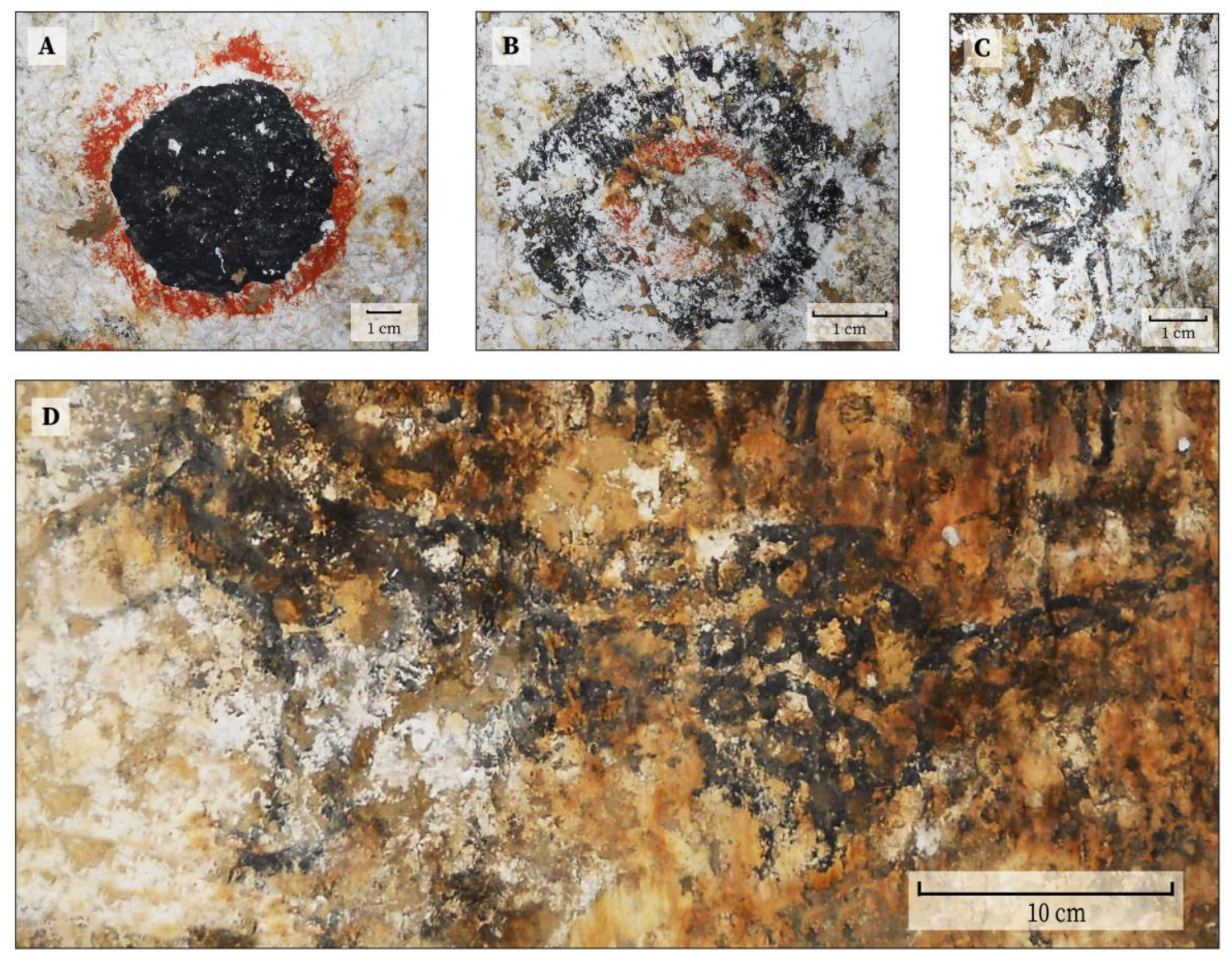

Figura 8. Diversos motivos en el arte rupestre de Cueva Inca Viejo. A y B. Círculos bicolores. C. Suri. D. Detalle del jaguar. 
En suma, la distribución de los paneles de arte rupestre en la cámara principal de la cueva como así también en los ingresos a las galerías secundarias tiene un alto impacto visual y comunicativo. Esta distribución parece corresponderse con la marcación de sectores de trabajo minero e ingreso a los socavones más importantes, hecho que permite señalar un claro vínculo entre el arte rupestre y la minería. A esta particularidad, debe agregarse que las pinturas de los paneles 1 a 4 se realizaron sobre paredes cortadas y trabajadas antrópicamente y que, en algunos contextos andinos, determinadas figuras han sido relacionadas con las prácticas mineras (e.g. antropomorfos con brazos alzados y el jaguar).

También es posible mencionar asociaciones de las imágenes dentro de cada panel, las cuales, en ciertos casos, parecen conformar escenas distintas. A modo de resumen, se puede señalar que en el panel 1 se localizan los antropomorfos de brazos alzados (A, B y C) en asociación con la caravana A guiada por un antropomorfo más pequeño. En este mismo panel, se observan los círculos bicolores y el suri, que parecerían no estar asociados entre sí y tampoco con la caravana. Allí se encuentran los antropomorfos de color rojo, posiblemente más tempranos. En el panel 2, hay camélidos esquemáticos aislados (dos de ellos en cópula), y otros dos alrededor de la figura de lados cóncavos con la diagonal doble en $\mathrm{X}$, que podrían remitir a una asociación escénica. En el panel 3, se encuentran otras figuras de lados cóncavos, mientras que en el panel 4 se distinguen camélidos en actitud dinámica y en cópula que podrían corresponder a una misma escena, una figura de lados cóncavos, el antropomorfo de los brazos alzados con felinos en los hombros, denominado D, y a su costado la caravana naturalista B y el jaguar. Si bien varias de estas figuras están próximas entre sí, no es posible inferir escenas compartidas entre los distintos motivos. Por ejemplo, no puede asociarse directamente la caravana B con el jaguar a pesar de compartir el mismo espacio de realización. El panel 5 tiene un único motivo caravanero, al igual que el panel 7. Por último, en el caso del panel 6, es factible plantear una escena vinculada con el conflicto a partir de antropomorfos con trompetas y posibles hachas o escudos.

\section{Comparación macrorregional}

Las manifestaciones rupestres de Cueva Inca Viejo muestran diversos atributos compartidos con las iconografías de otras áreas del Noroeste argentino y del Norte de Chile (Figura 9). Esta sección se focaliza en un análisis breve de los patrones comunes a nivel macrorregional registrados en las temáticas predominantes en el arte rupestre de la cueva. El estudio comparativo se centra en las figuras de camélidos y antropomorfos, dado que son las más recurrentes en Cueva Inca Viejo, aunque también se mencionan brevemente otras representaciones. 


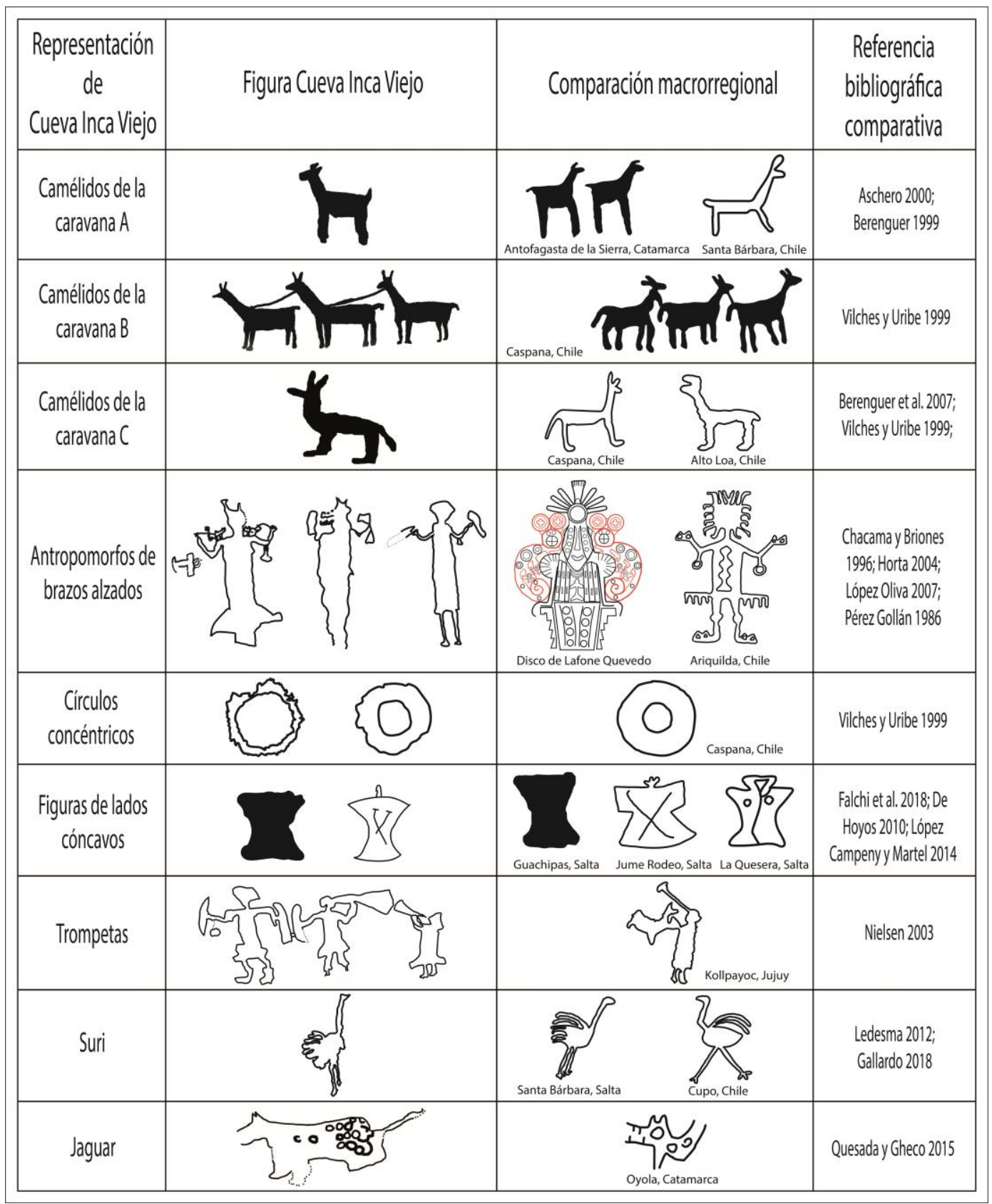

Figura 9. Comparación entre algunas representaciones rupestres de Cueva Inca Viejo y diversas iconografías de distribución macrorregional en el Noroeste argentino y el Norte de Chile.

Figuras de camélidos

En el caso de los camélidos, la primera comparación corresponde a los patrones relevados dentro de la temática caravanera. En la caravana A, el diseño de los animales en fila es esquemático, similar en algunos aspectos a lo observado en la fase Santa Bárbara en el Norte de Chile (Berenguer 1999). Esta clase de caravanas con camélidos en fila, y en algunos casos atados, se ha señalado como parte de los procesos ocurridos 
durante el denominado Período de Desarrollos Regionales, entre ca. 900 - 1400 DC (Nielsen 2003). Además resalta la presencia de una llama con carga, otro atributo del estilo Santa Bárbara, también relevado en el sitio Derrumbes en la Puna de Catamarca (Aschero 2000). De todas formas, la relación escénica con el antropomorfo de los brazos alzados podría retrotraer la cronología a contextos anteriores, en el denominado Período Medio (ca. 600 - 900 DC). Esta situación fue señalada por Aschero (2000) para camélidos de rasgos similares en Antofagasta de la Sierra, Puna de Catamarca. Se trata del patrón $\mathrm{HO}$ asociado con figuras humanas comunes en La Aguada (antropomorfos de los brazos alzados). Una particularidad de los camélidos de esta caravana en Cueva Inca Viejo es la presencia de las dos orejas, lo cual podría indicar una variante de estas representaciones.

La caravana B, por el contrario, presenta camélidos de diseño naturalista, por su morfología y las proporciones corporales. Aún cuando el patrón de los camélidos y las características de la caravana muestran aspectos singulares, la comparación en escala amplia permitió observar rasgos comunes en relación con motivos del Norte de Chile. Se observan atributos compartidos con un motivo caravanero de Caspana, en la cuenca superior del río Loa (Vilches y Uribe 1999). La caravana de Caspana también presenta camélidos atados y guiados por un antropomorfo. Además, los animales fueron dibujados con las cuatro patas, las dos orejas y los cuerpos pintados en negro, rasgos similares al patrón de los camélidos de Cueva Inca Viejo. Más allá de estas similitudes, los camélidos de la caravana B son naturalistas, a diferencia del motivo de Chile. La cronología de las pinturas de Caspana correspondería al Período Inca (Sepúlveda 2004; Vilches y Uribe 1999), lo cual se sustenta no solo por el patrón de los camélidos sino por la asociación con antropomorfos con vestimenta o unku con una diagonal doble en forma de X en su interior (Gallardo 2018). Este tipo de representaciones ha sido relacionado con los motivos de tocapus de las elites incas (Gallardo 2018) que, en el caso de Cueva Inca Viejo, se encuentra en una figura de lados cóncavos. A partir de todos estos indicadores, se plantea que la caravana B pudo haber sido realizada durante el Período Inca, aunque no puede excluirse una adscripción cronológica previa.

La caravana $\mathrm{C}$ también muestra diferencias con los motivos anteriores. Se trata de camélidos atados y guiados por un antropomorfo pero con atributos singulares, como la desproporción del tamaño de colas y orejas, y el detalle de manos y pies en las extremidades. Los camélidos de esta caravana tienen semejanzas con patrones observados en diversos sitios del Noroeste argentino y del Norte de Chile. Aschero (2000) expresa que el patrón H2c de camélidos tiene cuerpo corto, y cola y orejas algo exageradas. Estos rasgos se reflejan en el motivo de Cueva Inca Viejo y en sitios de la Quebrada de Humahuaca, Tafí del Valle y valles de Salta, entre otros (Aschero 2000, Falchi et al. 2018; Ledesma 2012). Aschero (2000) relaciona este patrón con algunas llamitas modeladas que acompañan las ofrendas de sitios incas de alta montaña. En Guachipas, Salta, se mencionan camélidos con autopodios en las extremidades. Falchi et al. (2018) enfatizan que este atributo de los camélidos es típicamente incaico. 
Las características señaladas también han sido observadas en el Norte de Chile, en una variante de camélidos del grupo A en la región del Loa (Berenguer et al. 2007). Este grupo tiene una cronología relativamente amplia en la región, pero se ha asociado con el Período Inca en el sitio SBa-518 del Alto Loa (Berenguer et al. 2007). Asimismo, este patrón fue asignado a contextos incaicos en Caspana, cuenca superior del Loa (Sepúlveda 2004; Vilches y Uribe 1999). En conjunto, los indicadores analizados en los camélidos de la caravana C de Cueva Inca Viejo parecen avalar la hipótesis que sitúa la realización de este motivo rupestre durante la expansión inca en los Andes centro-sur. Igualmente, dada su ubicuidad cronológica en otros sitios, al menos desde contextos tardíos preincaicos, se debe seguir profundizando en esta hipótesis a partir de nueva evidencia macrorregional.

Otras figuras relevantes de camélidos se encuentran en el sector noroeste de la cueva, en actitud dinámica y en algunos casos en cópula. La mayoría de este tipo de camélidos comprende motivos esquemáticos comunes en contextos tardíos preincaicos e incas. Su morfología remite al patrón H3 de Aschero (2000), aunque en Cueva Inca Viejo también se evidencian variantes más naturalistas de cuatro patas, principalmente los dos camélidos en cópula. Estos animales se encuentran enlazados o llevados a tiro, lo cual recuerda una imagen de Inca Cueva 1, Jujuy, de contextos tardíos prehispánicos (Aschero 2000). De todas maneras, en la figura de Inca Cueva 1, el camélido enlazado no está en cópula. En cambio, en Cueva Inca Viejo esta temática se encuentra en tres representaciones, evidenciando que no se trata de un caso aislado. Si bien se observan diferencias en la morfología de los camélidos, motivos similares de cópula se han registrado en los valles de Salta, siendo asignados al Período de Desarrollos Regionales (Falchi et al. 2018; Ledesma 2012). Aschero (2007) ha relacionado las imágenes de camélidos en cópula con prácticas rituales para el bienestar y la fertilidad de los rebaños. Asimismo, la mayoría de los camélidos de este panel encuentra similitudes con algunas variantes del grupo A del Loa superior, en el Norte de Chile, que perduraron hasta el Período Inca. También se pueden vincular con camélidos de Laguna Media, en la Puna de Jujuy, correspondientes a contextos incas (Yacobaccio et al. 2017).

\section{Figuras antropomorfas}

Una de las temáticas centrales de Cueva Inca Viejo es el denominado antropomorfo de los brazos alzados (e.g. Aschero 2000). Se distingue al menos en cuatro representaciones en el sector noroeste, en dos paneles distintos. En algunas de ellas se registra un vínculo con figuras felínicas. En el antropomorfo D, se detectan los dos felinos simétricos pintados en sus hombros. Estos felinos tienen una notable similitud con motivos de los valles de Salta (Falchi et al. 2018; Ledesma 2012). Los atributos mencionados remiten al famoso disco de Lafone Quevedo que muestra dos felinos simétricos alrededor de la cabeza radiada de la figura simbolizada (González 2004). Los antropomorfos de los brazos alzados han sido interpretados como deidades 
o personajes sobrenaturales de amplia circulación en el mundo andino en contextos prehispánicos, tales como el Punchao (deidad solar), el Personaje Frontal de Cabeza Radiada o el señor de los camélidos y/o los jaguares, entre otras denominaciones (Berenguer 1999; González 2004; Horta 2004). Se trata de un antropomorfo con atributos comunes a lo largo de los Andes pero que también tiene aspectos particulares según la región o el sitio. Horta (2004) ha sostenido que este personaje presenta una iconografía unificadora relacionada con un concepto religioso que, con variantes, circuló en el área Circumpuneña (ver también Aschero 2007). En espacios mineros del Norte de Chile, se ha planteado un rol social integrador y cohesionador de estas figuras (San Francisco y Ballester 2010). En consecuencia, podría postularse un rol similar para Cueva Inca Viejo, en el que este personaje mítico sirviera como cohesionador social, a partir del vínculo entre las actividades mineras y el mundo simbólico/sobrenatural plasmado en prácticas rituales.

Un indicador importante para comprender a estas imágenes antropomorfas son los elementos que cuelgan de los codos (Horta 2004). Estos elementos han sido considerados abstracciones de cabezas cercenadas y se han vinculado con la idea panandina del sacrificador (López Oliva 2007). A su vez, la presencia de felinos asociados o antropomorfos felinizados evoca a distintos personajes reflejados en diversos soportes, especialmente a partir de la expansión de Tiwanaco y, en el Noroeste argentino, de La Aguada. González (2004) ha planteado que las variantes de este personaje remiten tanto a la deidad solar Punchao como también al ser de los dos cetros y del sacrificador, distinguidos ampliamente en la iconografía de La Aguada. En esos motivos, son recurrentes los antropomorfos felinizados y los felinos, con fuerte evidencia desde el denominado Período Medio del Noroeste argentino (ca. 600 - 900 DC) pero que continúa después de ca. 1000 DC (Gordillo y Basile 2009; Pérez Gollán 1986). Este tipo de expresiones se refleja en la fase Isla, entre 300 y 1100 DC en el Norte de Chile (López Oliva 2007). En esta cronología, se hace evidente la proliferación del antropomorfo de los brazos alzados en distintas regiones de los Andes centro-sur, lo cual coincide con algunos fechados obtenidos en Cueva Inca Viejo. Inclusive se ha recuperado un fragmento de cerámica negra incisa con semejanzas estilísticas con La Aguada. Si bien esta vinculación cronológica y estilística no ha sido confirmada, esta hipótesis debe profundizarse debido a la continuidad de estos motivos con distintas transformaciones en sitios tardíos prehispánicos (Gallardo et al. 2012).

En otras áreas andinas, se han visto variantes de estos antropomorfos en contextos incaicos. De hecho, González (2004) subraya la continuidad de la deidad solar Punchao entre los incas, aun cuando presenta variaciones en relación con contextos más tempranos. En el caso de la caravana de Caspana, en el Loa superior, se observa una asociación con personajes con brazos alzados portando un tocapu en X (ver Vilches y Uribe 1999). En Cueva Inca Viejo, la cercanía en el mismo panel del antropomorfo de los brazos alzados de mayor tamaño con la caravana B y con la figura del jaguar llevaría a no desestimar la cronología tardío/incaica. De todas maneras resulta más 
probable, dadas las características generales de este antropomorfo, que la caravana B hubiese sido un motivo introducido posteriormente por el Imperio con el objetivo de resignificar las imágenes pintadas en ese panel. En este marco, es relevante la asociación de los antropomorfos de brazos alzados y los felinos (particularmente el jaguar), al encontrarse ambos motivos vinculados con espacios mineros andinos, similarmente a lo evidenciado en Cueva Inca Viejo

Otras formas antropomorfizadas corresponden a distintas figuras de lados cóncavos (Hernández Llosas 2001; Martel 2010; Ledesma 2012). En diversos contextos andinos, se han considerado como vestimentas correspondientes a cronologías tardías preincaicas e incas (e.g. unkus) (López Campeny y Martel 2014; Martel 2011). Sin embargo, también podría tratarse de escutiformes, tal como fueron interpretados algunos motivos similares en otras áreas de Salta como San Antonio de los Cobres o Guachipas (Falchi et al. 2018; Muscio 2010; Podestá et al. 2013). En el Norte de Chile, los escutiformes han sido denominados "personificaciones de hachas $u$ hombres hacha" $y$ han sido situados cronológicamente desde el Período Tardío preincaico (Intermedio Tardío) hasta la expansión inca (Montt y Pimentel 2009). Estos motivos también se han relacionado con espacios mineralizados del Norte de Chile (Montt y Pimentel 2009), lo cual sería relevante para comprender su presencia en la mina de Cueva Inca Viejo.

La diagonal doble en forma de $\mathrm{X}$ representada en el interior de una de las figuras de lados cóncavos se ha interpretado en otros sitios como un tocapu inca (Gallardo et al. 2012; López Campeny y Martel 2014; Montt y Pimentel 2009). Este tipo de motivos se encuentra en antropomorfos asociadas con caravanas, tanto en el Noroeste argentino como en el Norte de Chile (Martel 2010; Vilches y Uribe 1999). En el caso de Cueva Inca Viejo, esta figura no se registra directamente relacionada con una caravana, aunque se observan dos camélidos esquemáticos a su alrededor. Además, en el sector noroeste, la caravana B se correspondería presuntamente con un contexto Tardío/Inca. En consecuencia, los indicadores comparativos permiten situar esta figura antropomorfizada, con la diagonal doble, en el ámbito del arte rupestre inca (Figura 6 A). De todas maneras, dada la presencia de estas formas desde el Período Tardío preincaico o Intermedio Tardío (Montt y Pimentel 2009), incluso en urnas santamarianas del Noroeste argentino (López Campeny y Martel 2014), no se excluye que algunas de ellas hayan sido realizadas durante esa cronología. Al mismo tiempo, estas figuras marcan cierta continuidad entre contextos preincaicos e incas.

Por último, se ponen de relieve los antropomorfos pintados en el sector sudeste de la cueva. Se trata de los personajes con trompetas y posibles hachas o escudos. Este tipo de representaciones se ha vinculado con situaciones bélicas. Nielsen (2003) menciona la presencia de estos indicadores como una de las evidencias de una guerra endémica en contextos tardíos preincaicos, durante el Período de Desarrollos Regionales. En el arte rupestre del sitio Kollpayoc en la Quebrada de Humahuaca, se registran imágenes relacionadas con el conflicto, como antropomorfos con hachas y trompetas o cornetas 
(Nielsen 2003, 2007). Es interesante mencionar que varias de estas figuras son parte de un mismo panel con motivos de caravanas de llamas (Nielsen 2007). Se trata de temas comunes en Cueva Inca Viejo. Algo similar ocurre en sitios de la localidad de Guachipas, en Salta (Podestá et al. 2013). En dicha localidad, sobresalen escutiformes y hachas, además de camélidos y distintos antropomorfos (Falchi et al. 2018). A partir de la comparación macrorregional, es posible que los antropomorfos de Cueva Inca Viejo relacionados con esta temática reflejen guerreros o personajes vinculados con acciones bélicas o de conflicto, tal como ocurre en otras áreas del Noroeste argentino en contextos prehispánicos tardíos (Nielsen 2003, 2007).

\section{Otras representaciones}

A continuación, se consideran algunas representaciones relevantes para analizar aspectos cronológicos, y patrones de interacción macrorregional y transmisión cultural en escala amplia. En primer lugar, se hace referencia a los círculos bicolores (rojos y negros) en el panel 1. Este tipo de círculos, en algunos casos concéntricos, han sido asociados con la expansión inca. En Caspana, Loa superior, se encuentran distintos círculos en el mismo panel que los antropomorfos con tocapus y las caravanas de llamas (Vilches y Uribe 1999). Estos motivos, en conjunto, corresponderían al Período Inca. En el caso de Cueva Inca Viejo, las superposiciones y los patrones de diseño observados en el panel 1 podrían ser indicativos de diversas cronologías, las cuales abarcarían desde, al menos, el denominado Período Medio hasta contextos incaicos. La superposición ha sido comprobada directamente por la figura de un camélido negro sobre uno rojo. Tampoco se descarta la asignación al "Formativo Temprano" de algunas pinturas en rojo como las figuras de antropomorfos sumamente deterioradas.

Otras figuras reconocidas son el suri naturalista y el jaguar. El suri se encuentra en el panel 1 y presenta características similares a aquellos evidenciados en distintas áreas de los valles de Salta, asignados al Período de Desarrollos Regionales (Falchi et al. 2018; Ledesma 2012). En relación con el jaguar, su asignación cronológica es más compleja. Los atributos de este felino, dibujado en el panel 4 en la parte inferior de la caravana B, encuentran semejanzas con La Aguada por la amplia expansión de este tipo de motivos a partir del Período Medio. De hecho, un jaguar con fauces similares al de Cueva Inca Viejo fue asociado con este contexto cronológico y cultural en Oyola 11, una cueva localizada en la Sierra de El Alto-Ancasti, Catamarca (Quesada y Gheco 2015). Como en Cueva Inca Viejo, esa figura se encuentra cercana a un antropomorfo de los brazos alzados, también común en contextos de La Aguada. Más allá de estos aspectos, lo cierto es que la figura del jaguar ha sido asociada con el culto al otorongo en contextos mineros prehispánicos (Bouysse-Cassagne 2005; Platt et al. 2006). Incluso, no se desestima la realización de esta imagen en el marco de los rituales de producción mineros desarrollados por el Imperio inca en la cueva. 


\section{Discusión y conclusiones}

El arte rupestre registrado en Cueva Inca Viejo alude a temáticas diversas. Al respecto, es importante señalar que muchos patrones de diseño y temáticas descritos en la cueva muestran similitudes con iconografías de otras regiones del Noroeste argentino y del Norte de Chile. A partir de la caracterización y la comparación de las representaciones rupestres analizadas, se enfatiza el rol de los procesos de transmisión cultural compartidos a nivel macrorregional. Se plantea que la circulación de información cultural en escalas amplias fue fundamental para la distribución de rasgos iconográficos similares en los Andes centro-sur. Desde una perspectiva evolutiva, se propone que algunos mecanismos de transmisión cultural sesgados (Richerson y Henrich 2009) habrían posibilitado el traspaso de información acerca de diseños o temas (e.g. Muscio 2010). La distribución de figuras con atributos compartidos se acentuó a partir de contextos prehispánicos tardíos, lo cual se explicaría, entre otros factores, por el aumento en la amplitud y la distancia de las redes de tráfico caravanero (Aschero 2000; Muscio 2010). En este punto, cabe señalar el vínculo entre la transmisión cultural macrorregional y los procesos de interacción de escala amplia, principalmente relacionados con el caravaneo de llamas.

La recurrencia de motivos caravaneros en Cueva Inca Viejo constituye uno de los indicadores más visibles de esos procesos. En concordancia con estas manifestaciones rupestres, también se han recuperado sogas relacionadas con el atalaje de los camélidos y diversos elementos alóctonos, tales como semillas y plumas de diversas aves de las tierras bajas, que indican la circulación de bienes y recursos desde largas distancias (Araya 2017; López et al. 2015, 2018; Seguí 2019). La interrelación de estos registros permite sostener la importancia de Cueva Inca Viejo dentro de los procesos de interacción macrorregional, producto de prácticas caravaneras. Esta situación se habría profundizado en contextos incaicos, a partir de una mayor jerarquización social y del control de ciertos bienes y recursos en el marco del tráfico interregional. No puede pasar inadvertido que la comparación de los motivos caravaneros de la cueva haya permitido señalar su correspondencia, mayormente, con períodos Tardío/Incas. En especial, se ha propuesto que las caravanas B y C plasmadas en la cueva podrían haber sido pintadas durante la expansión inca en el área. En este marco, cobra un rol importante la explotación de turquesa de la fuente de Inca Viejo, una piedra preciosa muy valorada por las elites incas (López et al. 2018). Por tal motivo, se ha considerado factible que este recurso mineral hubiese formado parte de los procesos de interacción macrorregional relacionados con el caravaneo de llamas. En este aspecto, se ha señalado la existencia de espacios de minería cercanos a rutas de interacción y caravaneo, como así también el tráfico de los recursos mineros a través de estas redes de interacción (e.g. Garrido 2015; Núñez 1999). Cueva Inca Viejo pudo haber formado parte de esos circuitos, más tratándose de una fuente de turquesa. 
Tampoco puede omitirse el claro vínculo entre actividades rituales y económicas. La realización de pinturas rupestres prehispánicas sobre paredes cortadas antrópicamente por la minería y la depositación de una ofrenda con plumas en la entrada de la galería del sector norte, donde se encuentra la mayoría de los paneles, son algunos de los indicadores que permiten relacionar aspectos simbólico/rituales con aquellos económico/mineros. De hecho, la ofrenda constituye un ejemplo material de los rituales de producción en el mundo andino (Martel 2010; Van Kessel 1989).

Además de estos registros, se debe considerar que algunas de las figuras de la cueva tienen trascendencia sobrenatural o religiosa. Este es el caso de los antropomorfos con los brazos alzados que podrían vincularse con motivos de seres que tienen amplia replicación en los Andes, como el Punchao (deidad solar), el Personaje Frontal de Cabeza Radiada, el señor de los camélidos y/o los jaguares, e incluso, el sacrificador, mencionados en acápites anteriores (Berenguer 1999; González 2004; Horta 2004). Este personaje indica también la interrelación entre los aspectos simbólico/rituales y la circulación de información macrorregional a partir de procesos de transmisión cultural de escala amplia. Esta figura también ha sido replicada en espacios mineros prehispánicos de los Andes y ha sido relacionada con la integración y cohesión social de estos contextos y sus trabajadores a partir de un concepto o ideología religiosa común (San Francisco y Ballester 2010). La replicación de estas imágenes en Cueva Inca Viejo podría ser interpretada de la misma forma, más aún por ser un sitio minero. En este marco, las prácticas rituales habrían cumplido un rol fundamental en la transmisión de información clave para la reproducción social (Richerson y Henrich 2009). Estas prácticas podrían haber formado parte del culto al otorongo, de amplia circulación en contextos mineros. La imagen de un jaguar en el ingreso a una de las galerías abiertas en épocas prehispánicas, en cuyo espacio también se depositó la ofrenda mencionada anteriormente, indica un posible vínculo entre el culto al otorongo y la actividad minera en el sitio. Este culto, centrado en la figura del jaguar, habría actuado como cohesionador social para el compromiso de los grupos y como estimulador del coraje para realizar un trabajo extremo (Coloca y López 2021). El culto al otorongo no debe ser separado de las prácticas rituales asociadas, en especial aquellas relacionadas con el consumo de sustancias alucinógenas (e.g. cebil) y bebidas alcohólicas (e.g. chicha y aloja). La evidencia de Cueva Inca Viejo también es concordante con estas prácticas, puesto que se registraron semillas de cebil, marlos y granos de maíz (base de la chicha) y semillas procesadas de algarrobo (base de la aloja). A esta evidencia, también puede agregarse la posibilidad de que algunas figuras hubiesen representado hachas antropomorfizadas, que en el Norte de Chile han sido vinculadas con espacios mineralizados (Montt y Pimentel 2009). De esta manera, Cueva Inca Viejo podría estar mostrando un caso similar. Sin embargo, por el momento, no puede avanzarse en esta interpretación, dado que se debe profundizar en la comparación macrorregional acerca de la variabilidad de estas figuras. 
En síntesis, el conjunto de los indicadores mencionados previamente permite sostener el vínculo entre arte rupestre, minería y ritualidad en Cueva Inca Viejo desde contextos preincaicos hasta la expansión inca. Así, el arte rupestre habría jugado un rol crucial en la comunicación de distintas normas, creencias y valores comunes. A partir de la ocupación incaica, se habría producido una apropiación efectiva y simbólica de este espacio productivo y sagrado (e.g. Williams et al. 2005), evidenciado, entre otros indicadores, por la instalación de una estructura ceremonial en la entrada de la cueva. En consecuencia, el carácter sagrado y el valor económico-minero de Cueva Inca Viejo se habrían magnificado durante la expansión incaica. Esta apropiación simbólica de la cueva también se ve reflejada en distintas manifestaciones rupestres, presumiblemente pintadas durante el Período Inca. De todas maneras, tal como se evidencia en otros sitios de los Andes centro-sur (e.g. Vilches y Uribe 1999), la inclusión de pinturas rupestres de época incaica en las paredes de la cueva parece haber implicado una resignificación del carácter sagrado previo, más que una forma de eliminar las representaciones anteriores.

Por último, en relación con la cronología de las pinturas de Cueva Inca Viejo, se puede sostener que fueron hechas en contextos prehispánicos, al menos, desde ca. 650 DC hasta el Período incaico, a juzgar por la comparación macrorregional de los patrones de diseño y por los fechados obtenidos de las excavaciones en el sitio. Referido a este punto, las superposiciones de pinturas observadas en el panel 1 del sector noroeste indican la diacronía de realización. Se espera en un futuro próximo obtener nuevas muestras para fechar directamente por AMS algunas de las pinturas negras, en vista de que los análisis por EDX revelaron que, en el caso examinado, la composición sería mayormente compatible con material carbonoso. Al igual que el resto de la evidencia arqueológica, el arte rupestre de Cueva Inca Viejo parece haber tenido una fuerte impronta incaica, tanto en la representación de algunas caravanas de llamas como en la presencia de formas geométricas (principalmente círculos) y una figura de lados cóncavos con presunto tocapu. Más allá de estas características, las pinturas rupestres relevadas constituyen un testimonio material de cierta continuidad en la transmisión de información cultural y/o simbólica muy significativa para las poblaciones humanas que ocuparon este sitio, en la Puna de Salta, desde tiempos preincaicos hasta la expansión del Tawantinsuyu.

Agradecimientos: Al CONICET y a nuestros compañeros Sonia Araya, Federico Coloca y Juan Pablo Orsi. También agradecemos a Mariana Rosenbusch y al Centro Atómico Constituyentes (CAC) por los análisis de las muestras. Finalmente, agradecemos a los evaluadores anónimos y a los editores de la revista. 


\section{Bibliografía citada}

Araya, S.

2017 Análisis arqueobotánico de tres sitios ubicados en la Puna de Salta (Argentina) datados entre 2000-600 años AP. Cuadernos del Instituto Nacional de Antropología y Pensamiento Latinoamericano, Series Especiales 4 (3): 51-61.

Aschero, C.

2000 Figuras humanas, camélidos y espacios en la interacción circumpuneña. Arte en las rocas. Arte rupestre, menhires y piedras de colores en Argentina (ed. por M. Podestá y M. De Hoyos), pp. 15-44. Sociedad Argentina de Antropología y Asociación Amigos del Instituto de Antropología y Pensamiento Latinoamericano, Buenos Aires.

Aschero, C.

2007 Íconos, Huancas y complejidad en la Puna sur Argentina. Producción y circulación prehispánicas de bienes en el sur andino (ed. por A. Nielsen, M. Rivolta, V. Seldes, M. Vázquez y P. Mercolli), pp. 135-166. Brujas, Córdoba.

Aschero, C. y A. Martel

2003-2005 El arte rupestre de Curuto-5, Antofagasta de la Sierra (Catamarca, Argentina). Cuadernos del Instituto Nacional de Antropología y Pensamiento Latinoamericano 20: 47-72.

Berenguer, J.

1999 El evanescente lenguaje del arte rupestre en los Andes Atacameños. Arte rupestre en los Andes de Capricornio (ed. por J. Berenguer, F. Gallardo, C. Sinclaire, C. Silva y C. Aschero), pp. 9-56. Museo Chileno de Arte Precolombino, Santiago de Chile.

Berenguer J. R., G. Cabello y D. Artigas

2007 Tras la pista del inca en petroglifos paravecinales al qhapaq ñan en el Alto Loa, Norte de Chile. Chungara 39 (1): 29-49.

Bouysse-Cassagne, $\mathrm{T}$.

2005 Las minas del Centro-Sur andino, los cultos prehispanicos y los cultos cristianos. Bulletin de L'Institut Francais d'Études Andines 34(3): 443-462.

Cabello, G.

2017 Marcando yacimientos. Pinturas rupestres y minería en la región de Atacama, Chile (600-1300 D.C.). Tesis de doctorado, Facultad de Filosofía y Letras, Universidad de Buenos Aires, Argentina.

Chabert, $\mathrm{M}$.

1999 El pórfiro cuprífero Inca Viejo, Salta. Recursos Minerales de la República Argentina Anales 35 (ed. por E. Zappetini), pp. 1425-1436. Instituto de Geología y Recursos Minerales SEGEMAR, Buenos Aires. 
Chacama, J. y L. Briones

1996 Arte rupestre en el desierto tarapaqueño, norte de Chile. Boletín SIARB 10: 4151.

Coloca, F. y G. López

2021 Archaeology and pre-Hispanic mining rituals in the south-central Andes (Puna of Salta, Northwestern Argentina). Journal of Anthropological Archaeology 62: 1-12 (article 101275).

Falchi, M. P., M. A. Torres y L. A. Gutiérrez

2018 A orillas del Pirgua. Representaciones rupestres en el sitio Río Pirgua 1 (Guachipas, Salta). Arqueología 24 (1): 191-202.

Fiore, D.

2011 Materialidad visual y arqueología de la imagen. Perspectivas conceptuales y propuestas metodológicas desde el sur de Sudamérica. Boletín del Museo Chileno de Arte Precolombino 16 (2): 101-119.

Fiore, D.

2018 The materiality of rock art. Image-making technology and economy viewed from Patagonia. Archaeologies of Rock Art: South American Perspectives (ed. por A. Troncoso, F. Armstrong y G. Nash), pp. 23-57. Routledge, Londres.

Gallardo, F.

2018 Estilos de arte rupestre e interacción social en el Desierto de Atacama (Norte de Chile). Mundo de Antes 12(1): 13-78.

Gallardo, F., G. Cabello, G. Pimentel, M. Sepúlveda y L. Cornejo

2012 Flujos de información visual, interacción social y pinturas rupestres en el desierto de Atacama (norte de Chile). Estudios Atacameños 43: 35-52.

Garrido, F.

2015 Mining and the Inca road in the Prehistoric Atacama Desert, Chile. Tesis de Doctorado, University of Pittsburg, EEUU.

Giovannetti, M.

2015 Fiestas y Ritos inkas en el Shincal de Quimivil. Editorial Punto de Encuentro, Buenos Aires.

González, A. R.

2004 La arqueología del Noroeste argentino y las culturas formativas de la cuenca del Titicaca. Relaciones de la Sociedad Argentina de Antropología 29: 7-38.

Gordillo, I. y M. Basile

2009 Los unos y los otros: contraposición y reflexiones sobre universos expresivos del NOA prehispánico. Boletín del Museo Chileno de Arte Precolombino 24 (1): 153-179. 
Hernández Llosas, M. I.

2001 Arte rupestre del Noroeste argentino. Orígenes y contextos de producción. Historia Argentina Prehispánica (ed. por E. Berberián y A. Nielsen), pp. 389-446. Brujas, Córdoba.

Hongn, F. D. y R. E. Seggiaro

2001 Hoja Geológica 2566-III, Cachi. Provincias de Salta y Catamarca. Boletín 248 (ed. por el Instituto de Geología y Recursos Minerales), pp. 87. Servicio Geológico Minero Argentino, Buenos Aires.

Horta, $\mathrm{H}$.

2004 Iconografía del Formativo tardío del norte de Chile. Propuesta de definición e interpretación basada en imágenes textiles y otros medios. Estudios Atacameños 27: 4576.

Kerzter, D.

1988 Ritual, Politics, and Power. Yale University Press, London.

Ledesma, $\mathrm{R}$.

2012 El arte rupestre como expresión gráfica en las microrregiones Cafayate y Santa Bárbara (Salta). Comechingonia 16: 129-146.

López, G.

2020 Macro-regional interaction processes in the South-central Andes along the Holocene (ca.10000-500 BP): obsidian circulation, cultural transmission and evidence of allochthonous materials at archaeological sites in the Puna of Salta, North-western Argentina. Journal of Archaeological Science Reports 29: 1-11 (article 102187).

López, G. y F. I. Coloca

2015 El sitio Abra de Minas: nuevos aportes para la caracterización de las ocupaciones Tardío/Incas en las tierras altas del Noroeste argentino. Bulletin de l'Institut Français d'Études Andines 44(1): 141-149.

López, G. y F. I. Coloca

2019 Arquitectura ceremonial Inca en las tierras altas del Noroeste argentino: caracterización de los ushnus de Cueva Inca Viejo y Abra de Minas, Puna de Salta. Bulletin de l'Institut Français d'Études Andines 48: 229- 237.

López, G., F. I. Coloca y J. Orsi

2009 Ocupaciones humanas holocénicas en abrigos rocosos de la Puna de Salta. Comechingonia 12: 109-115. 
López, G., F. I. Coloca, S. Araya, J. P. Orsi y S. Seguí

2015 El sitio Cueva Inca Viejo, salar de Ratones, puna de Salta: evidencia arqueológica y procesos de interacción macrorregional. Relaciones de la Sociedad Argentina de Antropología 40 (1): 45-71.

López, G., F. I. Coloca, M. Rosenbusch y P. Solá

2018 Mining, macro-regional interaction and ritual practices in the South-central Andes: The first evidence for turquoise exploitation from the Late Prehispanic and Inca periods in Northwestern Argentina (Cueva Inca Viejo, Puna de Salta). Journal of Archaeological Science Reports 17: 81-92.

López, G., F. I. Coloca, J. P. Orsi, S. Araya, S. Seguí, M. Rosenbusch y P. Solá

2020 Ocupación incaica en Cueva Inca Viejo y Abra de Minas, Puna de Salta, Argentina: Minería de turquesa y prácticas rituales. Estudios Atacameños 66: 49-82.

López Campeny, S. y A. Martel

2014 La vestimenta del poder. Comparando los registros textil y rupestre en el Noroeste de Argentina (siglos XIII a XV). Relaciones de la Sociedad Argentina de Antropología 39 (1): 21-55.

López Oliva, M.

2007 Interpretación Simbólica de la Iconografía del Sacrificador y el Señor de los Cetros: Una Visión Desde los Mitos. Tesis de Licenciatura inédita, Facultad de Ciencias Sociales, Universidad de Chile, Chile.

Martel, A.

2010 Arte rupestre de pastores y caravaneros: estudio contextual de las representaciones rupestres durante el Período Agroalfarero Tardío (900 d.C.-1480 d.C.) en el Noroeste argentino. Tesis de Doctorado inédita, Facultad de Filosofía y Letras, Universidad de Buenos Aires, Argentina.

2011 El espacio ritual pastoril y caravanero. Una aproximación desde el arte rupestre de valle Encantado (Salta, Argentina). En ruta. Arqueología, historia y etnografía del tráfico sur andino (ed. por L. Núñez y A. Nielsen), pp. 111-150. Encuentro Grupo Editor, Córdoba.

Monteverde Sotil, L.

2011 La configuración arquitectónica de los ushnus como espacios de libaciones y ofrendas líquidas durante el Tahuantinsuyo. Bulletin de l'Institut Français d'Études Andines 40 (1): 31-80.

Montt, I. y G. Pimentel

2009 Grabados antropomorfos tardíos. El caso de las personificaciones de hachas en San Pedro de Atacama. Crónicas sobre la Piedra. Arte Rupestre de las Américas (ed. por M. Sepúlveda, L. Briones y J. Chacama), pp. 221-233. Ediciones Universidad de Tarapacá, Arica. 
Muscio, $\mathrm{H}$.

2006 Una aproximación evolutiva a la complejidad y al orden social durante el Período Temprano a través del estudio de representaciones rupestres. El caso de la Quebrada de Matancillas, Puna Argentina. Estudios Atacameños 31: 9 - 30.

2010 Representaciones rupestres tardías en Morritos, San Antonio de los Cobres, Puna de Salta: Observaciones e hipótesis preliminares. Comechingonia 13: 115-119.

Nielsen, A.

2003 La edad de los auca runa en la Quebrada de Humahuaca (Jujuy, Argentina). Memoria Americana 11: 73-109.

2007 Armas significantes: tramas culturales, guerra y cambio social en el Sur Andino Prehispánico. Boletín del Museo Chileno de Arte Precolombino 12 (1): 9-41.

Núñez, L.

1999 Valoración minero-metalúrgica circumpuneña: menas y mineros para el Inka rey. Estudios Atacameños 18: 177-222.

Pérez Gollán, J. A.

1986 Iconografía religiosa andina en el Noroeste argentino. Boletín del Instituto Francés de Estudios Andinos 3-4: 61-72.

Platt, T., T. Bouysse-Cassagne y O. Harris

2006 Qaraqara-Charka. Mallku, Inka y Rey en la Provincia de Charcas (siglos XV-XVII). Instituto Francés de Estudios Andinos/Plural editores/University of St. Andrews/University of London/Fundación Interamericana/Fundación Cultural del Banco Central de Bolivia, La Paz.

Podestá, M. y D. Olivera

2006 El contexto ecológico y económico del arte rupestre en la arqueología de la Puna Meridional Argentina. Kay Pacha. Cultivating Earth and Water in the Andes (ed. por P. Dransart (ed.), pp. 137-149. BAR International Series, Oxford.

Podestá, M., D. Rolandi, M. Santoni, A. Re, M. P. Falchi, M. Torres y G. Romero

2013 Poder y prestigio en los Andes centro-sur. Una visión a través de las pinturas de escutiformes en Guachipas (Noroeste argentino). Boletín del Museo Chileno de Arte Precolombino 18 (2): 63-88.

Quesada, M. y L. Gheco

2015 Tiempos, cuevas y pinturas. Reflexiones sobre la policromía del arte rupestre de Oyola (Provincia de Catamarca, Argentina). Relaciones de la Sociedad Argentina de Antropología 40(2): 455-476.

Richerson, P. y J. Henrich

2009 Tribal social instincts and the cultural evolution of institutions to solve collective action problems. Context and the Evolution of Mechanisms for Solving Collective Action Problems. Indiana University Bloomington. doi:10.2139/ssrn.1368756. 
Salazar, D., Berenguer, J. y G. Vega

2013 Paisajes minero - metalúrgicos inkaicos en Atacama y el altiplano sur de Tarapacá (norte de Chile). Chungara. Revista de Antropología Chilena 45(1): 83-103.

San Francisco, A. y B. Ballester

2010 La economía y las representaciones. Ensayo sobre la producción minerometalúrgica durante el periodo medio en la región de Atacama (III Región). Il Quattrocento 4: 139-159.

Seguí, S.

2019 Uso de recursos faunísticos durante los Períodos Tardío e Inca en Cueva Inca Viejo, Puna de Salta (Argentina). Cuadernos del Instituto Nacional de Antropología y Pensamiento Latinoamericano - Series Especiales 7 (2): 244-254.

Sepúlveda, M.

2004 Esquemas visuales y emplazamiento de las representaciones rupestres de Camélidos del Loa Superior en tiempos incaicos: ¿una nueva estrategia de incorporación de este territorio al Tawantinsuyu? Chungara 36 (2): 437-449.

Sepúlveda, M., F. Gallardo, B. Ballester, G. Cabello y E. Vidal

2019 El Condor mine: Prehispanic production and consumption of hematite pigments in the Atacama Desert, northern Chile. Journal of Archaeological Anthropology 53: 325-341.

Solá, P., H. D. Yacobaccio, M. Rosenbusch, M. S. Alonso, M. Maier, C. Vázquez y M. P. Catá

2013 Hematita vs. arcillas: su potencial como pigmentos rojos y su uso en tres sitios de la Puna jujeña (Argentina). Boletín del Museo Chileno de Arte Precolombino 18(1): 67-83.

Troncoso, A.

2011 Personajes fuera de lugar: antropomorfos tardíos en el arte rupestre del norte semiárido de Chile. Intersecciones en Antropología 12: 221-230.

Van Kessel, J.

1989 Ritual de producción y discurso tecnológico. Chungara 23: 73-91.

Vilches, F. y M. Uribe

1999 Grabados y pinturas rupestres tardías en Caspana. Estudios Atacameños 18: 73-88.

Williams, V. I., M. P. Villegas, M. S. Gheggi y M. G. Chaparro

2005 Hospitalidad e intercambio en los valles mesotermales del Noroeste argentino. Boletín de la PUCP 9: 335-373.

Yacobaccio, H. D., P. Solá, M. S. Alonso, M. S. Maier, M. Rosenbusch, C. Vázquez y M. P. Catá

2012 Pinturas Rupestres del Pleistoceno / Holoceno en la Puna de Atacama (Jujuy, Argentina). L'art pléistocène dans le monde / Pleistocene art of the world / Arte pleistoceno del Mundo. Actes du Congrès IFRAO 2010, Symposium Art pléistocène dans les Amériques 
(ed. por J. Clottes), pp. 751-772. Bulletin de la Société Préhistorique Ariège-Pyrénées, Tarascon-sur-Ariège.

Yacobaccio, H. D., P. Solá y M. Rouan Sirolli

2017 Una aproximación a la temporalidad de las imágenes de camélidos en Barrancas (Abdón Castro Tolay, Jujuy). IV Taller de zooarqueología de camélidos. GZC-ICAZ, Tilcara, Argentina.

Zuidema, $\mathrm{R}$

2014 The Ushnus of Cusco and Sacred Centres in Andean Ethnography, Ethnohistory and Archaeology. Inca Sacred Space: Landscape, Site and Symbol in the Andes (Ed. Por F. Meddens, K. Willis, C. McEwan y N. Branch), 5-28. Archetype Publications, Londres. 